\title{
La investigación dependiente: crítica estructural al sistema JCR
}

institucional.us.es/ambitos/

\section{Dr. Ramón Reig}

Universidad de Sevilla

ramonreig@us.es

English Version: Dependent research. A structural critique to the JCR system

\section{Resumen}

La investigación de habla hispana posee un considerable grado de dependencia de las formas y enfoques procedentes de los Estados Unidos. No es que sea negativo mirar a los Estados Unidos pero sí es negativo y alarmante "entregarse" a los Estados Unidos y renunciar a enfoques y estilos "tradicionales" del mundo latino y europeo. Y aún es más grave presentar las investigaciones bajo la "soberanía" del Journal Citation Reports (JCR) que, por mucho que se nos presente como institución científica, no por eso deja de depender de una corporación: Thomson Reuters. Y el conocimiento en Comunicación y Periodismo, en este caso, es dudoso que pueda

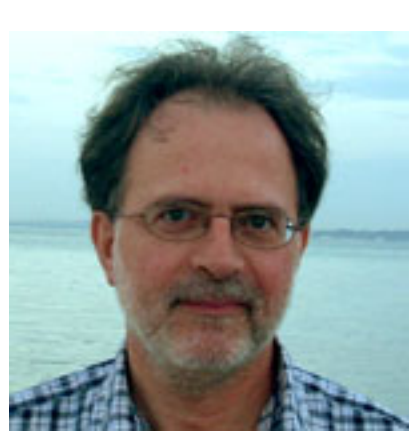
ser confiado al mercado, por muy democrático que afirme ser.

\section{Palabras clave}

Investigación, mercado, estructuras, poder, comunicación, periodismo.

\section{Abstract}

Spanish speaking research has a remarkable level of dependency on ways and approaches originating from the United States. Although having a look at the United States is not necessarily negative, we find negative and alarming "entrusting" this country and renouncing to latin and european "traditional" approaches. Of course, we consider even more serious the fact of presenting new research projects under the "government" of the Journal Citation Reports (JCR), which, despite being presented as a scientific institution, still depends on a private corporation: Thomson Reuters. Keeping this in mind, knowledge about Communication and Journalism should hardly be delivered to present market economy, no matter how democratic it claims to be.

\section{Keywords}

Research, investigation, market, economy, power, sctructures, communication, journalism.

\section{INTRODUCCIÓN: TRANSGRESIÓN DE LA 'ORTODOXIA'}

Adiós a las normas estrictas imperantes para poder editar un artículo universitario de investigación. Me arriesgo a que los nuevos "sanedrines" de la ciencia me acusen de lo que deseen: endogamia, prepotencia, falta de rigurosidad, estilo periodístico (es la acusación más ridícula y anti-académica que algunos evaluadores lanzan) [1]. Adiós a las prisas por editar para acumular méritos - ¿pasó a la Historia eso de que la paciencia es la madre de la ciencia?-, adiós a editar artículos técnicos llenos de formalidades y cuantificaciones funcionalistas a las que llaman ciencias sociales y humanidades, a las que llaman ciencia, cuando en no pocas ocasiones es simple complejo de inferioridad ante las otras ciencias "duras", y búsqueda de señas de identidad pretendidamente científicas.

Adiós a la "ciencia" servil y dependiente, introyectada incluso por eminentes colegas españoles y latinoamericanos. Adiós al paper for journal made in JCR firmado por varios autores cuando tal vez lo haya escrito uno de ellos y luego el resto deba escribir otro para aplicar eso de "hoy por ti, mañana por mí", con lo cual se va formando una bola de nieve de falsa calidad investigadora, llena de temáticas perfectamente 
prescindibles en buena medida que alejan a la universidad de la sociedad sin acercarla ni siquiera a los universitarios ni servir para que los propios expertos en el tema debatan o amplíen sus conocimientos. La única utilidad es que un comité oficial crea que los aspirantes a escalar peldaños en la carrera universitaria merecen llegar más alto y eso lo decide sin conocer a los autores ni cómo se han elaborado las investigaciones ni en qué consisten realmente. Sencillamente, el comité se basa en papeles que les colocan por delante y otorga valor especialmente a los que llegan con el marchamo JCR [2].

¿Qué es JCR? Algo valioso, sin duda, pero no por ello debe ser aceptado, sin más. Algo que ha sido mitificado por el mundo académico y sin embargo en realidad es un emporio macro-mercantil que dicta certificados de calidad o de invalidez académica. Numerosos profesores de los Estados Unidos parecen adorar a estas tres letras, las han convertido en una especie de Templo de Delfos. Y otros colegas suyos en otras zonas del planeta -empezando por España- se han contagiado del éxtasis jotacerrista a pesar de que -poseyendo un buen curriculum y un nombre en España y otros países- son menospreciados por académicos estadounidenses que los tratan casi como a doctorandos -o sin casi- cuando están de visita académica en alguna universidad concreta estadounidense [3].

Yo he publicado -que recuerde- en dos revistas JCR y he evaluado artículos para revistas JCR pero eso no me lleva a despreciar el valor del libro, por ejemplo, como hacen los jotacerristas, porque ahora, en España, se puede llegar a lo más alto del estamento académico sin haber sistematizado los conocimientos de una especialidad o disciplina académica en un buen libro. ¿Sin revisores por pares o por tríos a cargo de supuestas y misteriosas eminencias? La revisión de un artículo por expertos es muy recomendable, es lo menos malo, según Delgado-López-Cózar, Ruiz-Pérez y Jiménez-Contreras (2006):

El sistema de arbitraje científico ha venido siendo considerado como el eje fundamental de la publicación científica válida y de calidad. A pesar de los defectos que se han ido evidenciando (es lento, costoso, despilfarrador del tiempo de la comunidad científica, subjetivo, propenso al sesgo, permite abusos, es incapaz de detectar el fraude, el plagio y la publicación duplicada, no puede garantizar la validez externa de los trabajos), mayoritariamente se considera que, al igual que ocurre con la democracia, es el menos malo de los sistemas. [4]

Pero es necesario que se acoja siempre a criterios muy transparentes. Para empezar, el "sargento" no es conveniente que evalúe al "capitán general" ni el "fontanero" al electricista" ni siquiera el "cabo" al "sargento", o el "niño" al "adolescente" o el "adolescente" al "adulto", sin que eso signifique despreciar la opinión de unos y otros pero es que resulta que la igualdad no debe confundirse con la equidad y la democratitis derivada del pensamiento débil postmoderno tal vez esté equiparando senado con senectud y sénior con Alzheimer y colocando en la misma esfera a todos los curricula. En estos casos -y a mis maestros Schopenhauer (2012: 92-93) y Nietzsche (1999: 202-203) me remito- suelen vencer los muchos, es decir, los menos indicados y estamos tratando de conocimiento, no de confeccionar una lista "cremallera" electoral para unos comicios. Sin duda, hay cerebros brillantes excepcionalmente jóvenes que deben ser tenidos muy en cuenta pero el conocimiento más certero suele llegar con la edad. Repito: suele. Un investigador, en activo y lúcido, con diez, veinte, treinta años o más de trayectoria, podrá escribir textos más o menos buenos pero nunca impublicables, todo lo contrario, sólo sus planteamientos y su forma de razonar y analizar ya nos son de utilidad.

Espero que me esté expresando bien con estos símiles. Además, ¿cómo lograr desterrar las filias y las fobias, o las emociones que atoran a la razón y a veces confunden sentimientos políticos e ideológicos con ciencia y esos sentimientos son proyectados hacia la ciencia? Más claro y/o más concreto, ¿cómo confiar en la neutralidad científica de una revista editada por una universidad o centro adscrito a lobbies económicos, políticos o religiosos aunque se le tenga por un centro prestigioso? ¿Cómo confiar en una corporación como JCR que, como veremos, deriva de una situación a su vez emanada del Nuevo Orden Mundial de mercado?

Quede claro que estoy pensando siempre en las Ciencias Sociales y, dentro de ellas, en la Comunicación en general y en el Periodismo en particular (hay una ciencia que lo estudia, la Periodística: http://periodistica.es/), es decir, va más allá de un simple oficio, como era antes. El libro permite articular un pensamiento teórico o teórico-práctico, incluso una praxis pura y dura. ¿Quiénes lo evalúan? Los universitarios, los ciudadanos, los lectores de una editorial, no recuerdo conocer a autores destacados en Comunicación y Periodismo por sus 
papers sino por sus libros. A veces un paper no es más que una especie de divertimento. El paper es la orquesta de cámara, el libro es la orquesta sinfónica y una sinfonía exige organizar mucho mejor los elementos y un grado de trabajo incomparablemente mayor.

Me refiero a los libros que ven la luz en empresas con implantación. Se cuenta que una vez le preguntaron al escritor y periodista Francisco Umbral por qué era tan seductor con las mujeres y él respondió que ha tenido que seducir a más editores que mujeres. De todas formas, esto de las editoriales "prestigiosas" en ciencia es relativo porque hay temáticas -más en unos campos del saber que en otros- que sólo pueden aparecer en editoriales muy concretas o en editoriales institucionales porque el mercado rechaza ese tipo de temáticas. Eso sí, debe quedar muy claro que rechazo la autoedición y pagarse un libro con el dinero propio, siempre debe existir el elemento revisión y competencia en este tema porque, en efecto, en la actualidad, cualquiera edita un libro, pinta o compone música, etc. Lo que ha sucedido en Comunicación y Periodismo es que, en España, nos han introducido en el mismo saco y nos han mezclado y comparado con otras disciplinas "de paper" y entonces es cuando ha aparecido con fuerza el "síndrome JCR".

Aquí, en este paper herético, voy a cuestionar lo aparentemente incuestionable, sirviéndome de una metodología estructural. Voy a partir de unas bases teóricas que me van a facilitar dos colegas eminentes cuyos análisis los he extraído no de un paper (pido perdón por ello) sino de dos artículos periodísticos procedentes de dos diarios españoles de referencia (también pido perdón por eso, no son The New York Times ni The Washington Post sino El País y El Mundo). Dichos artículos ¡no están en inglés!, sino en castellano, no domino el inglés sino que es el inglés quien me domina a mí, esto se pone feo, tal vez deben dejar ustedes de leerme desde ahora mismo, mi paper no es paper ni es nada, es una estafa científica. A principios de 2014 me escribieron destacados cargos de Caixabank, me habían seleccionado para que yo, a su vez, seleccionara a futuros becarios con destino América del Norte. Cuando les advertí que no dominaba el inglés hasta tal extremo me dijeron adiós amablemente y me agradecieron mi honestidad.

Mi admirado colega Robert McChesney confiesa sin pudor que él desconoce la producción en español en mi especialidad que es la suya (las estructuras mediáticas, los sistemas de comunicación, las políticas de comunicación, las manipulaciones mediáticas derivadas de las estructuras de poder financiero-empresarialespolítico-mediáticas). Tratando sobre economía política de la comunicación en una entrevista con Nuria Almiron y Ana I. Segovia (2008) afirmó:

Lo que hay es unas pocas docenas de, podríamos decir, quizás, académicos en activo, que hacen economía política en los Estados Unidos, en Norteamérica, incluyendo Canadá, quiero decir en habla inglesa, no conozco la situación de México lo suficiente (...). No conozco lo suficiente la situación en el resto de Europa. Al trabajar sólo en inglés, no conozco los casos de España, Italia, Francia o Alemania pero conozco el caso británico y no percibo ninguna distinción entre investigadores británicos y estadounidenses, o británicos y canadienses, en el marco de la economía política, creo que es muy parecida a ambos lados del Atlántico.

$\mathrm{Y}$, sin embargo, yo sí me sumerjo en algunos de sus trabajos en inglés y en español y en el de otros estadounidenses [5]. ¡Claro! Es que son más importantes que nosotros, son del país del JCR. ¿Cómo publicar en una revista JCR sin citar ninguna referencia en inglés aunque no haga falta? ¿Cómo no va a hacer falta? Citar en inglés al menos en España es un valor añadido. Repito: aunque no sea necesario porque no se concibe que no sea necesario en nuestra investigación dependiente. McChesney puede afirmar sin rubor lo que se desprende de sus palabras anteriores: que, de su especialidad, sólo le interesa de verdad lo que se edita en inglés. ¿Quién lo censura por ello? Sin embargo, en España, sí amonestamos a quienes no siguen los trabajos angloparlantes y hacemos bien porque la ciencia es universal, lo único que sucede es que no lo hacemos exactamente por eso sino por entreguismo, por dependencia, por vergüenza, por falta de dignidad.

A pesar de todo, estoy seguro de que me entendería más o menos bien con McChesney si algún día lo conociera personalmente. $Y$ no me refiero al idioma sino a las concepciones relacionadas con nuestros campos de estudio. Debo estudiar mucho más inglés para comunicarme bien o decentemente con el Dr. McChesney pero todo llegará y, de lo contrario, no creo que ocurra nada sustancial en mi desarrollo. 
porque es accionista del grupo que lo impulsa: Prisa [6]. También es accionista de la multinacional petrolera Repsol [7], entre otras muchas empresas. El Grupo Carso, del mexicano Carlos Slim, es otro accionista de El País [8] y de The New York Times [9]. El Mundo es de la multinacional automovilística Fiat, ligada también a la industria de armamento (Reig, 2011a) [10]. The Washington Post es de Amazon (Jeffrey Preston Bezos) que al principio vendía libros - una industria cultural a fin de cuentas, como el propio diario- pero con el tiempo vende muchos más productos ajenos al periodismo (CDs, DVDs, juguetes, electrónica, ropa, comida, etc.) [11]. Eso sí, todos son diarios muy respetados, se lo dicen ellos mismos a sí mismos y lo afirman periodistas y profesores por todas partes. No digo lo contrario, sólo ofrezco datos reales cuando escribo esto, en mayo de 2014. Pero lanzo una pregunta y no lo haré en una sola ocasión: los periodistas de estos cuatro rotativos, ¿son realmente libres a la hora de investigar y escribir? Y respondo: no. Hasta el famoso Watergate fue una maniobra de utilización mutua periodismo-política para echar abajo al presidente Nixon. Ya se sabe: en Estados Unidos puedes criticar a los presidentes pero no a Coca Cola ni a Nike, que se lo pregunten a algunos reporteros de la CBS [12]. Un presidente está para recibir las bofetadas, como todos los políticos (qué gran estrategia de despiste del sistema), pero las grandes empresas son las esencias patrias mismas, sensibles como pétalos de rosa.

Las noticias -según se desprende de lo que dicen algunos autores desde hace tiempo (Merrill, Lee, Friedlander, 1992) al tratar, por ejemplo, del periodismo de investigación, en una línea muy estadounidense- están en lo público que, sin embargo, es el sector que menos puestos de trabajo crea, no en lo privado del que dependen miles de millones de personas. El periodismo se ejerce al revés, no en función del interés público sino del privado, y se identifica/confunde poder con Casa Blanca. Es fascinante pero los públicos no son estúpidos del todo y se están "vengando", abandonando poco a poco al periodismo y a los periodistas, su credibilidad -lo digo con todo el dolor de mi alma porque soy periodista- ha disminuido extraordinariamente en los últimos 25 años aquí y allá por eso [13], no por la presencia de las nuevas tecnologías en las que se han refugiado los receptores para evadirse de tanta impotencia y de tanta desinformación.

Para cumplir con estos tiempos de mundialización y dependencia este texto se edita también en inglés. He acudido para ello a un estadounidense, Jeffrey Trench, investigador en la Universidad de Sevilla (España), hombre inquieto, a la vez amante y preocupado por su país que es lo que define a un auténtico ciudadano patriota. Le doy las gracias. Quien tiene la tecnología tiene el idioma, por este camino cada vez se hablará menos español en contra de lo que se afirma por ahí. Los hispanos en Estados Unidos, de segunda, tercera y generaciones siguientes, nacidos en los propios EEUU, ¿qué idioma van a hablar? ¿Español? No, inglés, es lógico. Y, a muy largo plazo, para qué hablar español, eso queda en la familia, mejor inglés directamente. Los chinos y los alemanes se entienden entre ellos sobre todo en inglés (hasta los árabes), es más fácil que sus propios idiomas. Conste que a mí todo esto me parece científicamente fascinante, doy la enhorabuena a los protagonistas y autores de la mundialización por el mundo tan apasionante, misterioso y atractivo que están construyendo.

\section{HIPÓTESIS}

El apartado anterior nos ha colocado sobre la pista de un problema y del problema surge una hipótesis. En un acto académico le escuché decir a mi colega en la Universidad de Sevilla, el Dr. Juan Rey, experto en el análisis de los mensajes publicitarios, que las hipótesis pueden formularse en forma de pregunta. El problema detectado me lleva a preguntas centrales: ¿qué subyace tras las siglas JCR? ¿Puedo aproximarme algo a su significado desde el punto de vista estructural? Y a otras derivadas de las anteriores: ¿Qué está ocurriendo con la investigación en España? ¿Acaso se ha dejado "colonizar" en exceso por tendencias ideológicas y está perdiendo algo esencial en la investigación en ciencias sociales cual es el posicionamiento inconformista, crítico, creador, transgresor? ¿Acaso creemos que sólo es ciencia la llamada investigación aplicada? ¿Acaso no se puede aplicar aquello que cuestiona a los supuestos defensores de una investigación supuestamente aplicada?

\section{EL MÉTODO ESTRUCTURAL}

Acabo de expresar en la hipótesis que me interesa saber algo sobre lo que subyace a las siglas JCR. El método estructural de investigación busca precisamente lo que subyace a los acontecimientos. Existen opiniones muy 
superficiales y en general más cercanas a la ideología mercantil que al método científico, que identifican marxismo con enfoque estructural. No, el enfoque estructural contiene al marxismo y a la Escuela de Frankfort pero va mucho más allá y llega hasta visiones de amplio conjunto sumamente complejas. El enfoque estructural no es algo de derechas o de izquierdas, es la metodología de la articulación de elementos en su fase más compleja. No voy a detenerme apenas en citar las ideas de nombres ilustres de este método porque ya lo he hecho (Reig, 2010b, Reig, 2011b). Voy a tratar el tema con brevedad y basándome en ejemplos "de a pie".

Cuando Miquel Rodrígo Alsina y Miguel Beltrán (en Reig, 2010) se refieren al positivismo y al pensamiento o metodología crítica siguiendo a Neuman (1994) nos demuestran, a mi juicio, cómo una y otra escuela no son incompatibles. El positivismo busca la prueba empírica pero sobre una base teórica sistematizada; la escuela crítica persigue desentrañar los intereses ideológicos hegemónicos que se ocultan tras un discurso. ¿Por qué iban a ser opuestos? No, ambos están en el interior del enfoque estructural donde el Todo articulado es concepto base, un Todo que se deriva de la pregunta periodística (está en el lead de la noticia): por qué, que es además el punto de partida de la filosofía y de la ciencia la cual, no olvidemos, deviene de la filosofía.

Lo anterior nos lleva a estar de acuerdo con Marvin Harris (2000) cuando afirma: "Nuestra tarea como científicos [y yo añadiría como ciudadanos, y como periodistas] consiste en descubrir el orden en lo que se presenta como desordenado". Pero el enfoque estructural del que hablo persigue el orden de Todo a partir de un estudio complejo de la Historia. Complejo quiere decir interdisciplinario, las barreras ciencias-letras no sirven, entramos en la Filosofía Compleja de la Historia y en ella está la ciencia, está Todo.

Un ejemplo divulgativo del método estructural nos lo ofreció History Channel cuando se atrevió a emitir un documental titulado La Historia del Mundo en 2 horas, que ni siquiera eran dos horas sino una hora y treinta minutos [14]. En el documental se indicaba que nuestra historia tiene 13.700 millones de años, es decir, desde el Big Bang hasta la actualidad y que "todo está conectado". Esa conexión nos conduce al Todo y es ésa la tarea prioritaria que las ciencias sociales y las humanidades deben abordar o seguir abordando para ofrecer a la sociedad una ciencia muy aplicable que busca la casuística más profunda.

El enfoque estructural persigue que la persona no caiga en ingenuidades a la hora de comprender lo que ocurre a su alrededor. Aporto dos anécdotas significativas que pueden explicar mejor lo que acabo de afirmar. Una alumna de la Florida International University (FIU, Miami, USA) a la que impartí clases en Sevilla se sorprendió cuando comprobó que en la televisión española los informativos no se interrumpían a menudo para proyectar publicidad. Me preguntó la causa del hecho y le respondí que, entre otras, se busca con ello que el receptor no pensara que el periodismo depende mucho de la publicidad, que no diera la impresión de que los periodistas estaban totalmente sometidos en su trabajo a la publicidad. La alumna no comprendía bien aquello, tenía asumido en su cerebro que la publicidad no iba a molestar la libertad de expresión del periodista, es decir, aquella alumna había absorbido de forma acrítica un discurso tal vez hegemónico estadounidense.

La otra anécdota me la ofrece el cine. En la película JFK. Caso abierto (1991), de Oliver Stone, tenemos la célebre secuencia en la que Donald Sutherland -que encarna al personaje real Leroy Fletcher Prouty- le explica al intrépido fiscal Jim Garrison -interpretado por Kevin Costner- cómo funciona el Poder, mediante la articulación de los elementos: política, grandes empresas de armamento, finanzas, guerras, terrorismo de Estado, medios de comunicación, justicia, manipulación, espionaje... Tras el largo monólogo de Sutherland -al que Stone intercala símbolos del poder como el monolito cercano al Pentágono- el fiscal se queda atónito y exclama algo así como: "No creía que pudiera ser tan peligroso -se refiere a JFK- para la estructura de poder".

Que una alumna de la FIU, de unos 22 años, esté despistada podría ser comprensible, llevando a cabo cierto esfuerzo. También que otra joven universitaria estadounidense le preguntara en un debate al protagonista de la serie The Newsroom por qué los Estados Unidos es el mejor país del mundo, ante la incredulidad del personaje central (periodista y presentador de informativos) que, tras ser presionado por el moderador del debate, responde con tanta rotundidad que hasta deja a la chica en ridículo [15]. Pero que todo un fiscal no sepa cómo se desenvuelve la Historia y, dentro de ella, el Poder, es ya más inquietante si estamos hablando de un país que, a fin de cuentas, surgió de la mano de hombres ilustrados que hasta eran lectores de Karl Marx, como fue el caso de Abraham Lincoln [16]. ¿En qué universidad habían formado al fiscal de JFK? ¿Acaso en alguna que defiende a capa y espada el sistema JCR como el mejor del mundo también? [17] 
Los filósofos presocráticos ya estaban utilizando el enfoque estructural sin saberlo ni llamarlo así. El Bosón de Higgs no hace más que demostrar las teorías atomistas de Demócrito, Empédocles, Anáxágoras, Epicuro o Leucipo, entre otros, cuando todos ellos decidieron explicarse su entorno no a través de mitos sino a través de razonamientos deductivos (Matilde del Pino, 1999). No hay comprensión real ni esencial de nada sin el método estructural.

En mi caso, me he limitado, para este artículo, a utilizarlo de manera incipiente, "buceando" en la Red, buscando enlaces que me llevaran de un lado a otro a partir de las iniciales JCR. Ha sido la parte más empírica de este trabajo, sustentada en una pequeña fundamentación o puntos de partida y en algunos de los frutos que me otorga la experiencia de casi 25 años de docencia e investigación en Estructura de la Información. Claro que el enfoque estructural -como he sostenido- es mucho más hondo y complejo y nos conduciría mucho más lejos en nuestras pesquisas pero esa profundización no era el objeto de un trabajo como el presente.

\section{RESULTADOS}

Los apartados "Resultados" y "Propuestas" me están siendo familiares de un tiempo a esta parte. No era así cuando, en los años 80 y 90 del pasado siglo, me sumergía en tesis doctorales españolas. Empecé a encontrarme tales apartados en las tesis y trabajos de investigación en general de América Latina y entonces ya comprendí que el hecho se derivaba de la dinámica estadounidense. A mí no me importa adaptarme a esa dinámica como tampoco se la prohibí a los doctorandos latinoamericanos que me la exponían en los proyectos de las tesis que he dirigido pero he de puntualizar dos extremos: 1. Los resultados de una investigación van desde la primera letra de su título hasta la última de sus referencias documentales. 2. Las propuestas están contenidas en las conclusiones o deben estarlo. ¿Qué le propone -sobre todo- un investigador a quienes deseen escucharlo? El contenido de sus conclusiones. En este trabajo no habrá propuestas sino conclusiones y vamos a exponer ahora -cuando ya no procede porque estoy haciéndolo desde que comencé a redactar este artículo- los llamados resultados. Pero lo haré constatando que el método que estoy utilizando no es, en mi opinión, el más correcto.

\subsection{Puntos de partida}

Como indiqué en la introducción -y pedí perdón por la osadía- no van a ser dos papers made in JCR -o similares- mis puntos de partida sino dos artículos de prensa publicados, no por dos diarios de cabecera estadounidenses o ingleses -mi petición de clemencia también se derivaba de esta falta de rigor- sino por dos destacados colegas en dos diarios españoles de referencia (lo siento).

El primer punto de partida es el profesor Felipe Fernández-Armesto -inglés de nacimiento a pesar de su nombre- y su artículo titulado "La ciencia y su lucha por la supervivencia" [18] publicado el 5 de mayo de 2014 en el diario El Mundo. El segundo se refiere al profesor Rafael Argullol y a su artículo "La cultura enclaustrada" que vio la luz en el diario El País un mes antes, el 5 de abril de 2014 [19]. Para consultarlos, en ambos casos he utilizado las versiones digitales de los citados diarios: El Mundo.es y El País.com. Como es de sobra sabido, el lector de prensa de referencia ya es mayoritario en la Red mientras el papel va perdiendo enteros.

El profesor Felipe Fernández-Armesto es historiador y titular de la cátedra William P. Reynolds de Artes y Letras de la Universidad Notre Dame (Indiana). Por su parte, el profesor Rafael Argullol es catedrático de Estética y Teoría de las Artes de la Universidad Pompeu Fabra (Barcelona).

\subsubsection{La ciencia y su lucha por la supervivencia}

El texto del profesor Fernández-Armesto probablemente encierra una intención de crítica constructiva para Inglaterra, España y Europa pero eso no quiere decir que no estén presentes de manera más o menos explícita unas expresiones que se oyen a menudo en los medios de comunicación españoles, protagonizadas por los llamados contertulios o tertulianos de radio y televisión. Para indicar el camino recto a seguir descalifican a su propio entorno con "esto no pasa en Estados Unidos", "en Estados Unidos esto sería inimaginable"... Es una manía que se tiene en España y en América Latina: admirar lo ajeno en detrimento de lo propio sin detenerse apenas a destacar lo negativo que ocurre fuera de nuestro medio que, sin embargo, no sucede en él. Sin duda, es muy positivo tomar nota de las lecciones que nos dictan otros países y zonas del planeta pero para eso no 
hace falta descalificar lo propio o no abordar los defectos ajenos que pueden ser más graves que los nuestros.

Acabo de situar la carroza por delante de los caballos, eso no se hace en una investigación. Primero se colocan los hechos y luego se extraen las conclusiones, como en los tribunales de justicia, tal y como nos proyectan las múltiples películas estadounidenses de este género y sus remedos europeos. Pero a las personas mayores como yo se les deben permitir ciertos atrevimientos y, por si acaso no los permitían mis evaluadores ciegos, he llevado a término este acto de transgresión herética, endogámica, anticientífica y hasta presuntamente delictiva donde he consumado un tráfico de influencias a favor de mí mismo. Vayamos por tanto con los hechos para que me sirvan de atenuante en la sentencia condenatoria final.

En el arranque de su artículo, Fernández-Armesto sostiene que Estados Unidos, aunque como potencia tiene ya competidores en el mundo, no ha abandonado su protección y estímulo para con la investigación:

La preponderancia mundial de los EEUU está tocando a su fin. La hegemonía de una única superpotencia mundial se acabó. Otras economías son capaces de lanzarle un desafío. Pero Norteamérica sigue manteniendo su liderazgo en investigación científica, no sólo por la cantidad de dinero que se invierte, ni por la relativa importancia de la ciencia en la cultura nacional: el presupuesto por persona es más alto en Israel, Japón, Corea del Sur, Alemania, y varios países escandinavos. La ventaja estadounidense consiste en comprender mejor que los demás la naturaleza y las necesidades de la comunidad científica.

A continuación, el autor no prosigue con este tema de arranque -como sería lo necesario para argumentar mejor dicho inicio- sino que lleva a cabo unas reflexiones en torno a la ciencia para, al final, como veremos, cerrar el discurso volviendo al principio. Así:

La ciencia es un arte, o tal vez una ilusión. A nosotros, los seres humanos, que vivimos enredados en la naturaleza, no se nos permite una óptica objetiva. Somos incapaces de escapar la contextura aglutinante de la biosfera, que nos adhiere como a moscas pegadas al papel que las atrapa. Nuestra única salida es la imaginación. (...). La emoción y los sentimientos crean ciencia. Lo sabían los magos del Renacimiento y de la revolución científica de la Edad Moderna, conjurando efectos alquímicos mientras iban develando las estructuras de las materias, hechizando a los enfermos mientras iban curándoles, adivinando a los hados mientras trazaban el universo.

En el artículo, el autor se queja de que Richard Dawkins rechaza un guión suyo sobre Darwin no porque no fuera fiel a la realidad sino porque -a juicio de Fernández-Armesto- Dawkins tiene tan mitificado a Darwin que no admitió que su colega afirmara que los traumas físico-psíquicos de la familia de Darwin también le sirvieron al genial evolucionista para elaborar sus aportaciones a la ciencia. Por tanto, Fernández-Armesto infiere de ese episodio -y de otras observaciones y reflexiones- la necesidad de la ciencia como creación y, por consiguiente, como toda creación, la ciencia necesita ser libre y disponer de facilidades sociales para serlo:

la ciencia, tanto como las demás artes, necesita ser libre: libre de censura, libre de burocracia y libre de los comités de supuestos expertos, cuyo interés consiste en mantener las ortodoxias que ellos mismos formularon y siguen enseñando. Tanto como un poema o un llanto, una gran teoría científica es la creación de una mente, la criatura de una imaginación, la expresión de una emoción. Su terreno es la serendipia. Sus procesos son impredecibles. Pero en la Europa actual es casi imposible lograr fondos de investigación sin demostrar los resultados de antemano y someterse al juicio de especialistas poco originales, políticos mezquinos, y funcionarios faltos de imaginación.

Con el párrafo anterior puede afirmarse que mi ilustre colega me da alas para estar construyendo las líneas que tienen ante ustedes. En efecto, me he visto obligado a ello porque no deseo comparecer ante esos "especialistas poco originales" y menos ante "políticos mezquinos, y funcionarios faltos de imaginación". Sé que, con toda seguridad, existen en Europa, por supuesto en España, y en América Latina. Tal vez algunos de ellos sean los que han implantado unas normativas de ayudas a los proyectos de investigación europeos, uno de cuyos requisitos es defender esos proyectos en inglés ante un tribunal con lo cual les están ofreciendo privilegios a los ciudadanos de habla inglesa que en Europa son minoría y ni siquiera pertenecen al espacio euro [20]. Lo que ignoro es si existen en los Estados Unidos y si las exigencias angloparlantes de la Unión Europea (UE) en materia de apoyo a la investigación tienen que ver con ese amor hacia nuestro faro central de 
luz: Estados Unidos.

Por fortuna, el profesor Fernández-Armesto, según se desprende de su texto, es una excepción -nació en Londres- aunque relativa porque está criticando a Europa pero para ensalzar -finalmente, como se comprobará- a los Estados Unidos. Supongo que tendrá sus motivos para actuar así. En primer lugar, y para reforzar sus palabras anteriores, recurre a casos concretos:

Don Braben, catedrático honoris causa del University College de Londres, un gran inconformista de la comunidad científica inglesa, acaba de publicar Promoting the Planck Club -sostiene que ninguno de los 500 mayores científicos del siglo XX hubiesen conseguido fondos bajo el sistema vigente-. Entre los ejemplos que trata vienen Max Planck, Albert Einstein, J.J. Thomson, Ernest Rutherford, Niels Bohr, Werner Heisenberg, Barbara McClintock, Francis Crick, James Watson y Harry Kroto.

Braben hubiera podido añadir otros genios de la actualidad a su lista. Kary Mullis, por ejemplo, es un tipo que realiza trabajos innovadores no en el laboratorio sino dentro de su propia cabeza mientras va de surf o camina en su coche cupé. Pensó por primera vez en las reacciones de cadenas de polimerasas en 1983 mientras conducía de noche con una novia que luego le rechazó. Barry Marshall, otro Nobel, que ayudó a demostrar que unas bacterias son responsables de las úlceras pépticas, se mostró tan frustrado por la investigación convencional que se experimentó tragando una copa llena de bacterias como si fuera un cóctel. Cuando ofreció comunicar sus descubrimientos a un congreso de especialistas, se rechazó su ponencia por colocarse, según el reportaje del comité seleccionador, debajo del nivel obligatorio.

Nuestro autor anota otros casos similares a los anteriores. Como es imaginable, de todo lo anterior vuelve a deducirse la necesidad de llevar a cabo un cambio en Europa que permita seguir adelante con coherencia:

Si vamos a seguir adelante, si vamos a nutrir ciencia realmente innovadora, si vamos a liberar la potencia de los cerebros científicos, necesitamos a tales genios, por excéntricos y heterodoxos que sean. Y, por tanto, tenemos que encontrar medios de financiación que les permitan el ejercicio de esa creatividad sin límites que es imprescindible para practicar la ciencia -si se me permite expresarlo así- como arte.

Desde luego, el artículo, en mi opinión, es atractivo y oportuno. ¿Será posible lograr en España, en Europa y en América Latina, en la mayor medida posible, lo que expone nuestro colega londinense? Otros colegas podrían objetar que esa creatividad y libertad que reivindica Fernández-Armesto son unos de los factores que le han dado señas de identidad a Europa. ¿Acaso se han perdido? Tal vez pueda deducirse algo parecido porque mientras que, para el autor, en Europa tenemos, en ciencia, como evaluadores, "especialistas poco originales, políticos mezquinos, y funcionarios faltos de imaginación", da la impresión de que es distinto en Estados Unidos porque, como culmina su artículo Fernández-Armesto, se precisan métodos mejores para cuidar a los grandes cerebros $\mathrm{y}$ :

En EEUU existen tales métodos. Las grandes universidades disponen de fondos propios, protegidos por la legislación estatal y federal, que se distribuyen entre los investigadores, sin condiciones previas, en cantidades relativamente modestas pero suficientes para iniciar proyectos innovadores, desafiando a la sabiduría oficial. Yo mismo, que no soy sino un historiador humilde, cuyas investigaciones son baratas y de poco provecho al lado de las de mis colegas científicos, dispongo de tales fondos. Así los investigadores tienen la oportunidad de demostrar la utilidad de sus ideas antes de tener que solicitar el apoyo de los organismos burocráticos. Luego existen muchas fundaciones privadas en Norteamérica, enriquecidas por privilegios fiscales que en Europa ni somos capaces de concebir, que están dispuestos a fomentar propuestas de trabajo demasiado aventuradas para los accionistas, o demasiado extrañas para el orden dominante científico, o demasiado arriesgadas para el erario público. Tenemos que imitar ese sistema que sigue favoreciendo a la ciencia estadounidense en la competencia mundial. Pero ¿existe un Gobierno en Europa dispuesto a conceder tales libertades, o a fiarse tanto de los investigadores, o a lanzar una reforma tan profunda?

Me parece excelente que eso sea así, que tengamos en cuenta lo que ocurre en Estados Unidos, ya lo sabíamos en Europa y deberíamos tomar ejemplo, y pienso sobre todo en España que es lo que tengo más cerca. Ahora sólo hace falta que en el sur de Estados Unidos dejen de poner trabas a la enseñanza libre del darwinismo [21] y que en otros lugares y/o universidades ser partidario de la Economía Política de la 
Comunicación, la Información y la Cultura no deba llevarse escondido cuando no se ha llegado aún a cierto nivel en la escala profesoral por aquello de que te consideran "rojo" o también que las grandes empresas no patrocinen facultades o universidades porque, aunque nos encontremos en el país de la libertad, el dicho popular "donde hay patrón no manda marinero" aún posee mucha fuerza. Ni los Medici permitían ciertas licencias en el arte y la creación. En lo que se refiere a mis especialidad-el estudio de las estructuras de poder y su influencia en los mensajes comunicacionales-, ¿cómo voy a construir una auténtica metodología compleja estructural si los que van a ser criticados -por sus hechos- son quienes "alimentan" económicamente el centro desde el que investigo? Por supuesto que permitirían mi trabajo pero no indefinidamente, a través mía o de mis discípulos. En este sentido, tal vez estemos hablando de una creatividad dentro de unos márgenes, los márgenes made in JCR, por ejemplo, unos márgenes que son, a la vez, abiertos y muy estrechos: sus límites suelen ser las paredes de la universidad.

Si no fuera cierto lo que digo, ¿por qué la existencia en Estados Unidos del Project Censored (http://www.projectcensored.org/) o del citado FreePress http://www.freepress.net/), entre otros organismos? ¿Por qué ha sido necesario crearlos? Evidentemente, pueden poseer financiación privada, de fundaciones, e incluso pública pero eso nos lleva a otro tema más complejo: el reforzamiento del sistema mediante el apoyo a instituciones y personas que lo rechazan, o sea, la estrategia del reforzamiento del sistema mediante su negación y estímulo -controlado- a quienes lo cuestionan o rechazan. Es una de las grandes virtudes estadounidenses, tal vez la mayor: primero prender la llama del incendio, luego llamar a los bomberos para que lo apaguen y todo eso presentarlo a la opinión pública como libertad aunque el resultado final sea que los problemas permanecen o se acrecientan. Es, en efecto, el logro de la cuadratura del círculo.

\subsubsection{La cultura enclaustrada y otras críticas}

Rafael Argullol coincide con Fernández-Armesto en su preocupación por el "enclaustramiento" de la capacidad creativa aplicada a la ciencia. Pero se centra más en el caso español-que es paradigma del panorama existente en buena parte de América Latina y al revés- y en acotar aún más el asunto al ámbito universitario. Sin embargo, da la impresión de que se queda corto al no hacer ni mención del sistema JCR, tan certero por una parte, no lo dudo, pero al que nos hemos entregado con pocas críticas, al menos explícitas, porque a niveles individuales y orales existen. No obstante, después anotaremos algunas de las que se han publicado.

Los dos autores me han sido tremendamente valiosos como puntos de partida de este trabajo y como fundamentación teórico-metodológica porque -aunque no se exprese de manera clara en los artículos de ambos- se desprende de sus textos la necesidad de analizar los hechos bajo el enfoque estructural. Los dos estudiosos proceden de las ciencias sociales y de las humanidades. Fernández-Armesto es historiador y Argullol, filósofo práctico, si me permite que lo defina así. Es lógico que estén preocupados por la libertad de investigación y por la parcela creativa. Yo me he formado en ambos campos y además en el antropológico, el comunicacional y el periodístico, un oficio que, durante quince años, me ha permitido salir de mí mismo, pisar calle y relacionarme con el poder y con el Poder. Mi preocupación procede de la inquietud ante el hecho de que el ser humano deje de ser humano, demasiado humano -los que deseen serlo, tal vez una minoría- y se entregue, sin saberlo ni ser plenamente consciente de ello, a posturas epidérmicas que en el fondo encierran una ideología de dominio.

A veces me he sentido como un personaje de la película Fahrenheit 451 (1966), dirigida por François Truffaut, bajando de la Red documentación audiovisual por si Google decide censurarla, como de hecho ya me ha ocurrido en otras ocasiones. Después he pensado también que, independientemente de que el hecho siga ocurriendo y lo haga con mayor intensidad en un futuro, la estrategia del reforzamiento del sistema mediante su negación no necesita acudir a tales torpezas, como han hecho en China, en Irán o en Cuba. Basta con "lavar el cerebro" del receptor potencial para que él mismo se autoexcluya de acudir a esa documentación de valor cognitivo sincrónico si se sabe utilizar bajo el enfoque metodológico estructural (o ignore que exista). Como he afirmado en otros lugares (Reig, 2011b), arrebátale al ser humano el método de comprensión de su contexto y macro-contexto, ofrécele herramientas para su evasión y entretenimiento de acuerdo con sus tendencias más elementales y ya puedes jugar con él como desees a la libertad, la democracia, el emprendimiento, el pluralismo mediático, la libertad individual y el teórico libre mercado. 
Como he dicho, Rafael Argullol creo que piensa más en el caso español y es más rotundo y concreto en sus apreciaciones. Además, cita expresamente a la fiebre del paper como un aspecto tóxico de la dinámica universitaria:

La universidad se ha replegado sobre sí misma como consecuencia de un nuevo antiintelectualismo favorecido por una sacralización del 'paper', cuya confección obliga a renunciar a toda creatividad y riesgo.

Nuestro pensador añade a la necesidad de la creatividad la del riesgo, he aquí una diferencia con el artículo de Fernández-Armesto quien no trata este tema con personalidad propia aunque se deje entrever. La sacralización del paper -y ahora se trata de mi parecer- nos lleva a la sacralización o mitificación -como he indicado más arriba- del JCR, su máxima expresión. También en Argullol aparece la figura del burócrata y la burocratización como elemento negativo:

El universitario ha elaborado normas en las que no se reconoce el talante intelectual. Apenas se reconoce el talante intelectual, abierto y crítico, que se halla en la raíz renacentista de la universidad. Dicho de manera brutal: el humanista ha sido arrinconado por el burócrata.

En mi opinión, las normas que el universitario ha elaborado no proceden exactamente de la tradición europea, española o latinoamericana, se supone que son necesarias y, como he afirmado una y otra vez, no pocos de mis colegas sénior las han aceptado, las promueven, las celebran y se han tornado en conversos, convencidos de que lo nuestro estaba corrupto de arriba abajo y, en lugar de arreglar el desaguisado sobre la base de nuestra Historia, se ha acudido a los principios de la cultura mercantil más hegemónica. Puedo reforzar lo anterior con las palabras del propio Rafael Argullol:

En la actualidad una gran mayoría de profesores ha descartado la escritura de libros como labor primordial para concentrarse en la producción de papers. En muchos casos esta renuncia es dolorosa pues frustra una determinada vocación creativa, a la par que investigadora, pero es la consecuencia de la propia presión institucional, puesto que el profesor debe ser evaluado, casi exclusivamente, por sus artículos supuestamente especializados. Como quiera que sea, el nuevo microcosmos en el que se encierra a la universidad traza una kafkiana red de relaciones y hegemonías notablemente opaca para una visión externa a la institución. Además de atender a sus labores docentes, los profesores universitarios emplean buena parte de su tiempo en la elaboración de papers, textos con frecuencia herméticos, destinados a denominadas "revistas de impacto", publicaciones que tienen, por lo común, escasos lectores — siempre del propio ámbito de la especializaciónaunque con un gran poder ya que son las únicas "que cuentan" en el momento de evaluar al universitario. En consecuencia, los profesores, sobre todo los jóvenes y en situación inestable, hacen cola para que sus artículos sean admitidos en publicaciones de valor desigual pero insoslayables. Se conforma así una suerte de mandarinato que rige el microcosmos. Los profesores son calificados, mediante las evaluaciones oficiales, de acuerdo con el acatamiento a aquellas normas. La ilusión o vocación de escribir obras de largo alcance —algo que requiere un ritmo lento, que a menudo abarca varios años— debe aplazarse, quizá para siempre.

Herrán y Villena (2012) han cuestionado también la situación que denuncia Argullol pero en referencia a la investigación en los campos de la didáctica y la organización escolar y su relación con lo que llaman "La cultura del impacto JCR". En esta línea, han escrito:

Lo que parece perseguirse es calidad. (...). Pero por la orilla de la Universidad ha entrado un tsunami que nos ha arrastrado a una situación muy delicada. (...). La comunidad científica se encuentran dividida entre la obligación de investigar con el mayor cuidado y calidad posibles y rendir cuantitativamente. Esta fina andadura por encima del alambre tiene lugar mientras que -como ocurre en casi todas las profesiones- una materia prima básica de todo intelectual -el tiempo- escasea más y más cada curso y cada día.

Es grave la sospecha de Argullol sobre la pérdida de ilusión por escribir libros académicos. En agosto de 2013 falleció el profesor Mariano Cebrián Herreros, catedrático de Periodismo de la Universidad Complutense de Madrid, con amplia experiencia profesional e investigadora en el terreno de la comunicación audiovisual. Estamos ante el experto español más citado internacionalmente en su especialidad en la que, por cierto, quien firma este artículo figura en el lugar número 11, según datos del $H$ Index Scholar de la Universidad de Granada (España) [22]. El profesor Cebrián, en conversaciones conmigo, era muy crítico con la resistencia a escribir 
libros y colocaba el mérito de un buen libro -evaluado y sistematizado- muy por encima de cualquier paper a pesar de los muchos papers que llevan su firma.

El libro es especialmente valioso en ciencias sociales y humanidades. Afirmé antes que los dos autores que estamos siguiendo como puntos de partida desarrollaban su labor en estos campos. No es de extrañar la preocupación de Argullol ante la tecnificación de las ciencias sociales y de las humanidades y su sometimiento a la burocracia angosta de unas normas apabullantes y estrechas de edición y evaluación. Nuestro filósofo argumenta:

Este ensimismamiento de la universidad, si merece críticas crecientes en el ámbito de las ciencias, (...) es directamente desastroso en el de las humanidades, puesto que erradica la figura creativa e intelectualmente abierta para imponer un perfil del profesor sometido a las servidumbres de un pequeño mundo que se presenta como "especializado" pero que, en realidad, es puramente endogámico. Lo peor es que este pequeño mundo, que alardea de rigor académico, se hace implícitamente cómplice del antiintelectualismo populista, al refugiarse en un lenguaje oscurantista y críptico. Podría confeccionarse una auténtica antología del disparate si juntáramos las exigencias burocráticas que, en el presente, rigen la vida universitaria. Entender las normas del microcosmos requiere tantas horas de estudio que apenas queda tiempo para estudiar lo demás. Comprender cómo hacer el paper servilmente correcto obliga, por lo general, a renunciar a toda creatividad y a todo riesgo.

Para comprender lo que de forma tan rotunda sostiene Rafael Argullol, el lector no tiene más que conectar con un enlace ya citado en este trabajo [23]. Es un simple ejemplo de una selva de normas y disposiciones en la que parece que la originalidad y la ciencia transgresora no tienen lugar, es el rendimiento, sometimiento y pleitesía al requisito documentalista en sus más mínimos detalles así como la dependencia del secretismo del revisor o lector desconocido o no -lo más generalizado es la primera opción- que puede estar evaluando un texto con un contenido que ni siquiera domina con la misma altura que su autor. Y es la dependencia de la llamada investigación aplicada que es como denomina la ideología mercantil a todo lo que le interesa, en primera instancia, para desarrollar su actividad y su objetivo principal: producir mucho al menor coste posible.

\subsection{Teoría y praxis}

Completemos ahora la teoría anterior y ampliémosla con la praxis correspondiente. Por lo pronto, los contenidos de los dos puntos de partida expuestos nos llevan a una serie de inferencias parciales:

- Si todo es tan positivo y asequible en Estados Unidos, si existen tantas instituciones de apoyo a la ciencia, ¿por qué esa "obsesión" estadounidense por el paper para journal JCR?

- A Rafael Argullol tal vez le falte una mayor profundización en su crítica, no "toca" para nada el tema JCR.

- Por tanto, la teoría debe ser confrontada con la praxis.

¿Cuáles son algunas de las causas que nos han llevado a desembocar en esa dependencia acrítica del sistema JCR? Nos las explican Delgado López Cózar, Ruiz Pérez y Jiménez Contreras (2006):

Una de las actividades de la Fundación Española para la Ciencia y la Tecnología (FECYT) consiste en apoyar la profesionalización e internacionalización de las revistas científicas españolas. Muchas de estas revistas, especialmente de las áreas de Ciencias Sociales y Humanidades, apenas están representadas en bases de datos internacionales. Esta infrarrepresentación se atribuye, entre otros motivos, a la calidad insuficiente de las revistas, que les impide competir en el mercado internacional de la información científica. Entre los problemas detectados, cabe destacar las reticencias al uso del inglés, la baja profesionalización de los equipos editoriales, la falta de regularidad en la publicación, pobre distribución y escaso o insuficiente control científico de los contenidos. En un círculo vicioso, estas publicaciones, siempre sacadas adelante con gran esfuerzo y dedicación, no consiguen atraer las miradas de los científicos de alto nivel de su área de conocimiento, lo que les impide mejorar sus contenidos. La nula o escasa visibilidad de ciertas revistas científicas españolas provoca que los trabajos de investigación en ellas publicados apenas sean leídos y citados, en otras palabras, que apenas tengan impacto. 
David Fernández Quijada (2008) enlaza con este análisis pero ya coloca unos primeros elementos críticos que, en buena parte, basa en Delgado López Cózar, Ruiz Pérez y Jiménez Contreras:

En los últimos años, la actividad de la Comisión Nacional Evaluadora de la Actividad Investigadora (CNEAI) y de la Agencia Nacional de Evaluación de la Calidad y Acreditación (ANECA) y el resto de agencias de evaluación autonómicas ha privilegiado el Journal Citation Reports como parámetro central de la calidad de la actividad científica. En el caso de las ciencias de la comunicación, normalmente a través del Social Sciences Citation Index (SSCI), que como el resto de índices de Thomson, contiene sesgos que ya han sido determinados: preponderancia de publicaciones en inglés, sobrerrepresentación de la investigación anglosajona o preeminencia de las ciencias puras y la tecnología frente a otras disciplinas (...). Las ventajas que ofrece, por otro lado, se pueden resumir rápidamente: visibilidad e impacto de la producción científica.

Entonces, dado el "desastre" detectado, ¿cuál es el modelo preferente a seguir? Está claro: el modelo JCR. Esto nos conduce a la praxis, al análisis del "ente" JCR que marca la diferencia entre calidad y menos calidad o no calidad [24].

\subsection{Praxis, aportación empírica}

Cuando los investigadores españoles pretendemos que nos reconozcan nuestros méritos a nivel oficial (lo que conocemos como sexenios o tramos de investigación) acudimos primero a las normativas correspondientes para saber sobre qué basamento legal tendremos que guiarnos con el fin de que nos digan si hemos trabajado bien o mal. Después presentamos unos papeles y una comisión -que jamás nos entrevista, que no ha leído nuestro quehacer intelectual y que está compuesta por colegas de distintas ciencias sociales, en el caso de la comunicación y el periodismo (por cierto, casi nunca hay periodistas académicos en estas comisiones)-, una comisión, estaba diciendo, dictamina si nos merecemos o no ir consolidando méritos como investigadores. $Y$ esa comisión actúa tal y como he indicado.

En el caso español, es lamentable que, habiendo sido elevados los estudios de periodismo a nivel universitario desde los años setenta del pasado siglo, en las comisiones evaluadoras de la investigación en Comunicación y Periodismo apenas estén presentes colegas que hayan sido cocineros antes que frailes, es decir, que hayan ejercido la comunicación y/o el periodismo antes de investigar académicamente hablando y de dedicarse a la universidad. Se trata de un extremo esencial porque el curriculum de un periodista académico dista bastante de otros tipos de curriculum. La metodología investigadora académica de alguien que ha ejercido la profesión durante diez, veinte o treinta años no tiene por qué coincidir con otras metodologías y no por ello es menos meritoria. Sin embargo, el trabajo de un investigador en comunicación y periodismo es evaluado por expertos en Psicología, Sociología, Economía, Antropología... Y viceversa. No dudamos de la aptitud de ninguno de estos colegas pero sí de su especificidad para tan altas responsabilidades. Ni la Comunicación ni el Periodismo son ciencias subsidiarias de ninguna otra ni ninguna otra lo es con relación a la Comunicación y el Periodismo.

Pues bien, como iba diciendo, el investigador español en Comunicación y Periodismo o en algún otro campo, al interesarse por las normativas orientadoras para medir la calidad de su trabajo, encuentra por ejemplo esta dirección a seguir:

Se valorarán preferentemente los artículos incluidos en revistas recogidas en los "Journal Citation Reports del Social Science Citation Index" y el Science Citation Index (Institute for Scientific Information, -ISI-, Philadelphia, PA, USA) [25].

Mi primera pregunta es obvia: ¿dónde me quieren llevar para otorgarme sello de máxima calidad?En primer lugar, al "Journal Citation Reports del Social Science Citation Index" (JCR). Entonces, para empezar, y de acuerdo con el enfoque metodológico estructural antes descrito, mi segunda pregunta es evidente: ¿qué es el Journal Citation Reports (JCR)? Herrán y Villena (2012) constatan:

El sistema de evaluación de la producción científica establecido radica en una creación del Dr. Eugene Garfield (n. 1925), fundador del Institute for Scientific Information (ISI), hoy de la empresa Thomson Reuters Science. En 1955 revolucionó la investigación científica con el concepto de indexación de citas e investigaciones. Garfield vendió ISI a Thomson Reuters. Desde entonces no se llaman ISI las bases de Thomson Reuters. Thomson 
Reuters Science es una división de Thomson Reuters Corporation. Se autodefine como "la fuente líder en el mundo en información inteligente para investigadores". Provee cobertura a las revistas regionales e internacionales de mayor influencia en todo el mundo. Su producto estrella es Web of Knowledge (WOK), una plataforma con una extensa cantidad de información, herramientas y tecnología integradas. En ella incluye la base de datos Web of Science (WOS), un producto de recuento de citas en publicaciones científicas, actualizado desde 1900, que actualmente cubre a unas 12.000 revistas de varios campos: Ciencias Naturales, Química, Ciencias Sociales y Artes y Humanidades. La WOK se apoya en el siguiente principio, conocido como Ley de Bradford: La literatura básica de una disciplina científica se publica en revistas con gran relevancia, que definen el núcleo de la ciencia que tratan, y las de poca relevancia, que interesan a otras disciplinas. Por tanto, sería poco práctico e innecesario indexar a todas las revistas del mercado, porque sólo un reducido número de revistas publica la mayor parte de los resultados científicos importantes.

La primera conclusión es clara: fuera del JCR "hace frío", alguien se ha delegado la función de otorgar los diplomas de calidad a las revistas científicas mundiales, supongo que sobre la base de lo que nos recordaba el profesor Fernández-Armesto: que Estados Unidos es la primera potencia mundial en investigación y en entender a los investigadores. ¿También en Comunicación y Periodismo? ¿En todo? Y aunque así fuera, ¿no hace falta un consenso internacional? ¿Adoptamos sin más, dócilmente, el sistema JCR por muy positivo que sea, que sin duda lo es? Los citados Herrán y Villena no dudan en afirmar:

La autoatribución de "liderazgo de pensamiento" o portador de información "esencial" en los campos científicos que incluye no sólo parece pretencioso y poco autocrítico, sino que puede aproximarse a un cierto adoctrinamiento epistemológico obviamente peligroso y científicamente rechazable.

Al asentar tendencias y autorías dificulta el desarrollo de emergencias o de propuestas heterodoxas. Según un estudio promovido por la propia Thomson Reuters, de las 7.621 revistas en todo el mundo que son incluidas en el JCR de 2008, tan sólo 300 representaron más del $50 \%$ de lo que se citó y más del $30 \%$ de lo que se publicó. Un núcleo de 3.000 revistas cuenta con más del $90 \%$ de los artículos citados y más del $80 \%$ de los publicados. Si bien se reconoce que los núcleos científicos no son estáticos, su sistema enfatiza estándares de ciencia, la recurrencia y la permanencia de los círculos científicos dominantes que se nutren y citan entre sí, y no aspectos que no tienen por qué guardar relación con la exclusión o la inclusión de nuevas revistas en la base de datos de Thomson Reuters. Piénsese por ejemplo que a cualquier revista -JCR o no- le interesará más que en ella publiquen las habituales firmas de prestigio que un autor heterodoxo y desconocido, independientemente de la relevancia o utilidad de su trabajo, porque recibirá más citas.

Otras objeciones de los dos mencionados autores -Herrán y Villena- pueden resumirse así:

- Que el sistema coadyuve a que el medio sea el fin es, al menos, cuestionable. Como se ha descrito, Thomson Reuters identifica y evalúa para su inclusión en sus listados a nuevas revistas que considera prometedoras y elimina de los informes JCR a las que se han vuelto menos útiles.

- El poder que se le otorga al sistema organiza la producción y su uso como si lo que ocurriera fuera de ellas no existiera o no sirviera para promocionar en el campo de la calidad y del reconocimiento científico. $Y$ lamentablemente, éste es el mensaje tácito que se transmite a quien investiga y a las revistas: 'Si tu trabajo no está aquí, no vale'. Por tanto, el sistema incide indirecta y negativamente en quienes por razones diversas quedan fuera porque no pueden o porque no quieren.

- Relacionado con el anterior, pretende implícitamente minusvalorar los análisis y procedimientos para cuestionar, por ejemplo, la carrera docente.

- Como las revistas españolas no se citan tanto como otras, se añade el problema local de las relativamente pocas revistas españolas indexadas en el JCR, lo que hace que los trabajos de investigación se intenten publicar en medios extranjeros JCR para mejorar los propios listados, lo que refuerza el sistema emisor-gestor de Thomson-Reuters.

- Hoy la función básica docente-investigadora, que es generar conocimiento, ya no es suficiente. Es preciso publicar ciencia de determinada manera y en lugares concretos. De ello dependerá, quizá, su desarrollo 
profesional, su investigación, su financiación o su trabajo universitario por las exigencias de los sistemas de evaluación a los que nos hemos apegado. Por ello, en muchos casos, los científicos han pasado de investigar a redactar (...). El sistema establecido coloca a quien investiga en la universidad más cerca de la fabricación que del sosiego, del interés personal que del humanismo del que toda ciencia se nutre, del esquematismo y de las formas arbitrarias y rígidas que del contenido, de los papers que del ensayo. Y esto se nos antoja una contradicción científica y de sentido común, particularmente importante si de enseñanza y educación se trata. Por tanto, el problema puede asociar implicaciones para la investigación, pero serán de mayor calado las repercusiones formativas. Y éste es un problema pedagógico de primera magnitud.

El mencionado David Fernández Quijada (2008) nos recuerda una serie de hechos clave al escribir interesándose: por el sentido de publicar en revistas internacionales temas de marcado acento local. Más allá del anclaje territorial, una posible respuesta es la posibilidad de comparar metodologías y herramientas de investigación que pueden ser aplicadas en otros contextos. No obstante, ese interrogante remitía irremisiblemente a cuestionarse por el español como lengua de transmisión de la ciencia. Una pregunta cuya respuesta parece obvia en ciencias sociales pero que se responde con una rotunda negación en áreas como ciencias naturales, médicas e ingenierías. En este sentido, el inglés se ha convertido en la lengua vehicular de comunicación científica a nivel internacional, lo que supone diversos problemas para los países en los que ésta no es la primera lengua. Entre otros, el papel de gatekeepers o guardianes de teorías, metodologías y temáticas dominantes que se arrogan los investigadores anglosajones (...), los que más publican en estas revistas y que forman parte de forma mayoritaria de sus comités editoriales y de revisión. Sirva como ejemplo de ello los datos aportados por Masip (2005) sobre la procedencia de los autores que publicaron entre 1994 y 2004 en las 35 revistas incluidas en la sección de comunicación del JCR y que también estaban accesibles desde la base de datos Communication Abstracts (...). El dominio estadounidense era apabullante: el $66,89 \%$ de los artículos tenían esa procedencia. Los tres siguientes países también eran del ámbito anglosajón, mientras que España se situaba en una discreta decimosexta posición con 43 artículos, menos de 4 anuales.

Otro dato aportado por Masip es suficientemente significativo: cinco revistas concentraban más del $50 \%$ de la producción europea, que sólo era mayoritaria en cuatro de ellas. Es cierto que existen bases de datos alternativas que cubren las ciencias sociales (y entre ellas la comunicación), como Scopus, propiedad de la multinacional holandesa Elsevier. A finales de 2007, además, Scopus inauguró una alternativa de acceso libre para la consulta del factor de impacto, el SCImago journal \& country rank, desarrollado en España por el grupo interuniversitario Scimago (...). Aunque la selección de revistas en el área de comunicación es más amplia que en el caso del JCR (53 títulos frente a 44), los sesgos continúan siendo básicamente los mismos, ya que la lengua de difusión y los países de edición pertenecen al mismo ámbito.

Claro que si no hay más autores españoles, ¿se debe a que somos unos incompetentes o a las directrices que se denuncian? Quienes conocemos el montante de estudios en Periodismo y Comunicación en España -y bastante de América Latina- me parece que no podemos sostener alegremente que en el mundo angloparlante se investigue más y mejor sobre Periodismo y Comunicación (Moragas, 2011, Marques de Melo, 2009, León Duarte, 2007) [26]. Creo que el problema posee raíces de mayor calado y que hay que tener en cuenta las palabras de Jaume Soriano:

La producción científica realizada en lengua inglesa está sobrerrepresentada y se ignoran las investigaciones divulgadas en otras lenguas. Este sistema también infrarrepresenta las investigaciones realizadas al margen de las corrientes o paradigmas dominantes de una disciplina, así como las investigación de carácter más exploratorio.

\section{$(\ldots)$}

La evaluación de la investigación científica mediante criterios bibliométricos plantea objeciones adicionales cuando la disciplina sobre la que se aplica pertenece al área de las ciencias sociales y humanas, como es el caso de la investigación en comunicación. Las diferencias epistemológicas entre las ciencias naturales y las ciencias sociales afectan de manera muy especial a la medición de ésta mediante procedimientos bibliométricos. (...). Una de las primeras diferencias reside en que los objetos de estudio de las investigaciones en este campo suelen tener una orientación más local, menos universalista, y por consiguiente la difusión e 
impacto de los resultados de esas investigaciones suele tener unos límites nacionales o regionales bien definidos; en segundo lugar, las ciencias sociales y humanidades se caracterizan por ser áreas de conocimiento multiparadigmáticas, por lo que la literatura científica se presenta de forma mucho más fragmentaria y heterogénea; y en tercer lugar existe una mayor pluralidad de formatos con los que se difunde el conocimiento en las ciencias sociales y en las humanidades a diferencia de las ciencias naturales. [27]

Jaume Soriano ha demostrado con un pequeño experimento la disminución de los artículos que se derivan de los saberes sincrónicos y el aumento de los contenidos digamos técnicos entre 1994 y 2006 , estudiando las revistas españolas en comunicación de mayor impacto en esos años, lo que me lleva a inferir que, en efecto, se ha ido adoptando poco a poco un camino que tiene más que ver con la ideología implantada desde ciertos centros de poder mercantil que con los enfoques tradicionales españoles, europeos y latinoamericanos. El llamado pensamiento único no sólo se halla en la sociedad en general sino también en el mundo supuestamente científico.

Todo empezó, por tanto, con el Dr. Eugene Garfield. Un pequeño vistazo por la Red nos permite saber que se trata de un "informatólogo", licenciado además en Química, con formación en biblioteconomía que ha pasado por las universidades de Columbia, Colorado, Berkeley... Pero lo que ahora nos interesa más es la actual definición que de sí misma efectúa JCR:

Journal Citation Reports $®$ offers a systematic, objective means to critically evaluate the world's leading journals, with quantifiable, statistical information based on citation data. By compiling articles' cited references, JCR helps to measure research influence and impact at the journal and category levels, and shows the relationship between citing and cited journals. Available in Science and Social Sciences editions. [28]

Lo anterior es mera promoción, publicidad. Mi metodología nos lleva más allá: ¿qué subyace tras las siglas JCR? Aportaré una pequeña ilustración propia, como todas las que aparecerán más adelante:

\section{Subyace una corporación multinacional angloparlante:}

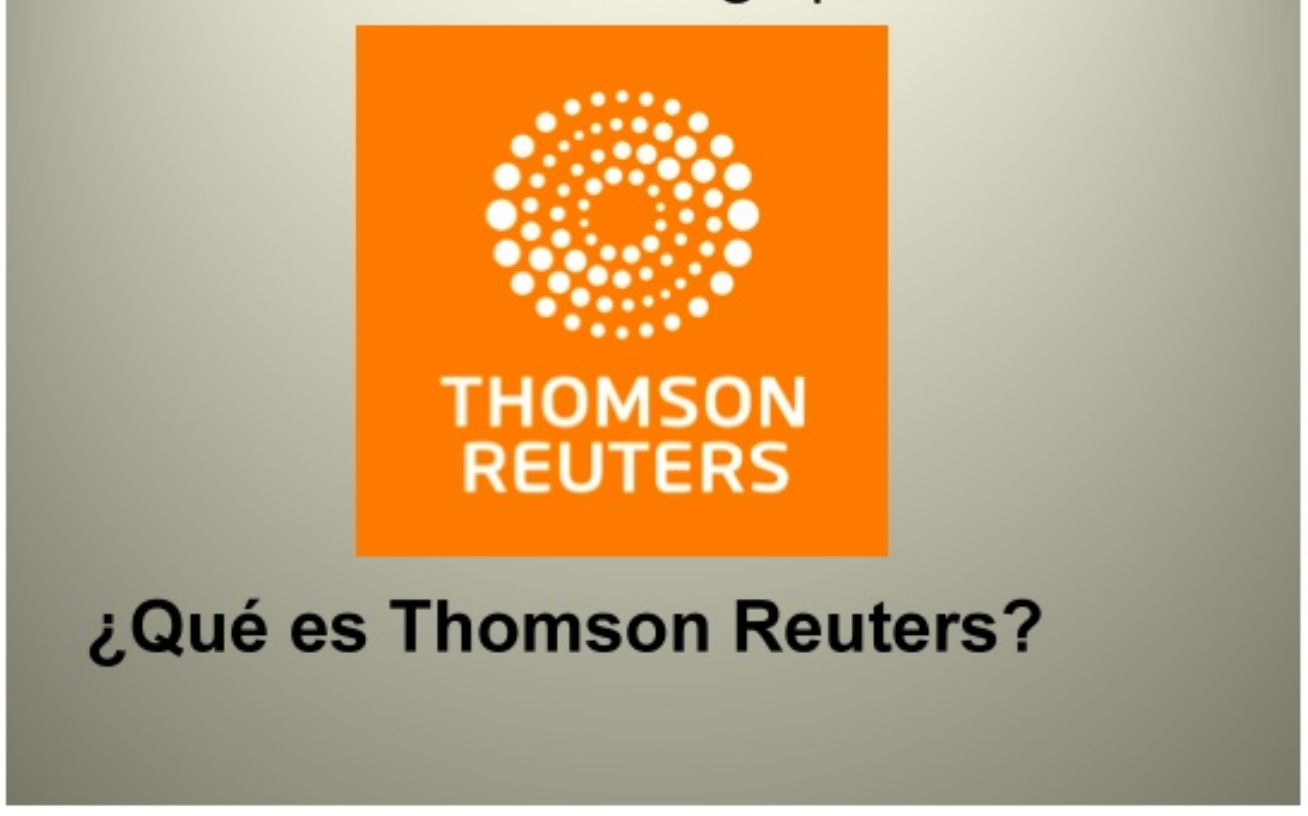

El 27/3/2008, el citado diario El Mundo, de España, informaba: "Una corporación nueva nace de la fusión de Thomson (Canadá-USA) y Reuters (RU) con un valor de unos 12.000 millones de euros" [29]. Eso fue en 2008 pero antes actuaba The Thomson Corporation que operaba a través de cinco segmentos: Thomson Financial, Thomson Healthcare, Thomson Legal, Thomson Scientific, y Thomson tax \& Accounting. Aunque la compañía ha estado siempre vinculada a los medios de comunicación también ha tenido sus incursiones en la aeronáutica (propietaria de Britannia Airways después llamada Thomsonfly) y explotación de los yacimientos de gas y petróleo del Mar del Norte. Sin embargo, en la actualidad se nos presenta oficialmente como una firma de servicios de educación, información y comunicación, sobre todo financiera, ya unida a Reuters. 
Siguiente pregunta en mi proceso metodológico aunque pueda parecer simple o innecesaria: ¿Qué es Reuters?

- Aunque es más conocida por su labor como agencia de noticias, esto sólo supone el $10 \%$ de los ingresos totales del grupo.

- La principal actividad de Reuters consiste en proveer información a los mercados financieros.

- Entre sus competidores se encuentran Bloomberg L.P. y Dow Jones Newswires.

- Desde 2008, forma parte de Thomson Reuters.

- Bloomberg es propiedad de Michael Bloomberg, exalcalde de Nueva York.

- Dow Jones edita The Walt Street Journal, propiedad de News Corp. (Rupert Murdoch). (Reig, 2011a).

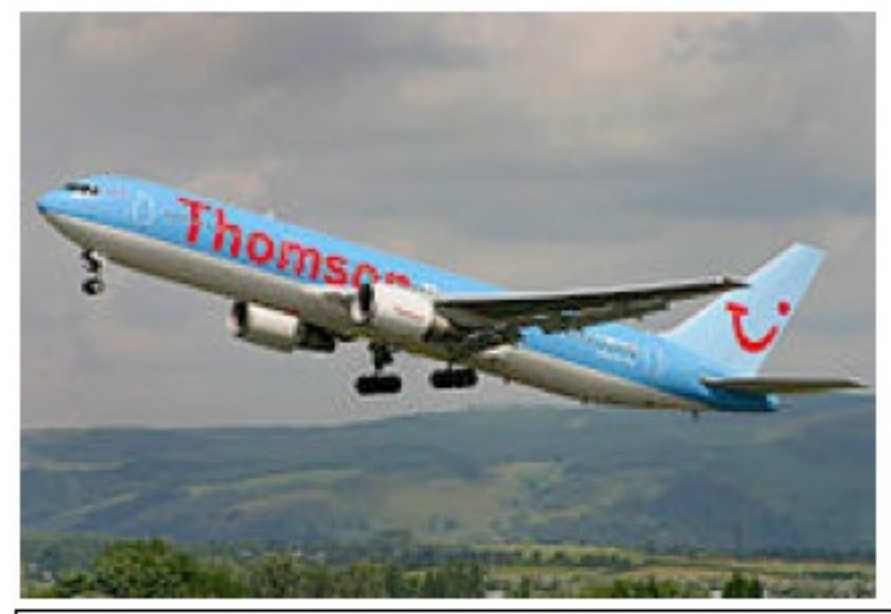

A Thomsonfly Boeing 767-300ER takes off from Glasgow International Airport, Scotland, (2006). Fuente: http://en.wikipedia.org/wiki/Thomsonfly

O sea, que Thomson Reuters se halla inmersa en el mundo del mercado de la comunicación. El siguiente paso de mi investigación me lleva a interesarme por una mínima muestra de los nombres que han impulsado o impulsan Tomson-Reuters. De nuevo acudo a una ilustración:

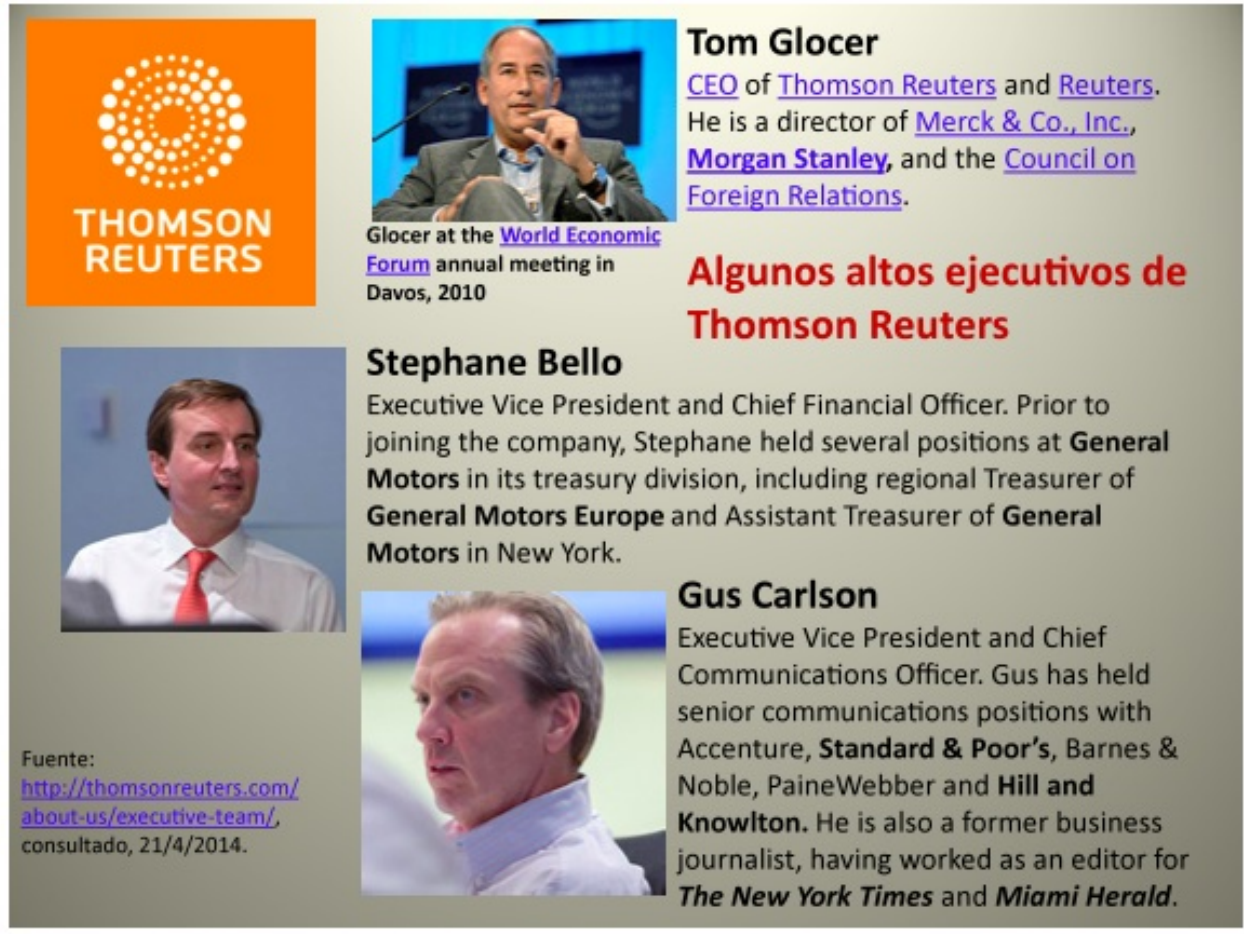

Tom Glocer, Stephane Bello y Gus Carlson nos introducen en las siguientes grandes empresas, entre otras:

- Morgan Stanley.

- General Motors.

- BlackRock.

- Hill and Knowlton

El enfoque estructural relacionado con la Economía Política de la Comunicación, la Información y la Cultura 
(EPICC) posee un aspecto crucial a tener en cuenta para entender lo que está sucediendo en el interior del mundo cognitivo y mediático: los procesos de concentración y diversificación del capital propios de la economía de mercado y, aún más, de la nueva economía derivada de la mundialización y de la sociedad en red, conducen a que sea tanto o más habitual que las grandes empresas compitan como que colaboren entre ellas en procesos de joint venture. Así es cómo se ha ido formando -en nuestra época contemporánea desde el siglo XIX- una telaraña socioeconómica que por supuesto incluye a los medios de comunicación que también son empresas, organizados en grupos y conglomerados conectados con firmas ajenas a la comunicación y viceversa: firmas de comunicación que diversifican su presencia accionarial hacia sectores extraños a la comunicación misma (Reig, 2010a). Únase a todo ello la presencia de la política.

Sobre la base de lo anterior, primero tiraré -algo- del hilo de Morgan Stanley y así podré comprobar dónde me lleva esta empresa. Lo representaré así:

\section{Articulaciones MorganStanley}

- En enero $\underline{2008}$ la entidad española La Caixa compra parte del negocio de banca privada de Morgan Stanley en España por un importe que ronda los 600 millones de euros.

- Entre los accionistas de Morgan Stanley están Mitsubishi UFJ Financial Group, Inc., BlackRock Institutional Trust Company, N.A. y JP Morgan "laCaixa" Chase \& Company. (https://es.finance.vahoo.com/a/mh?s=MS), consultado, 21/4/2014.

- La Caixa es accionista de Telefónica y Prisa.

- BlackRock posee alrededor del 10\% de Televisa.

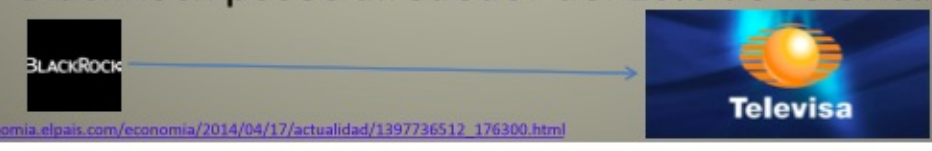

Fuente: http://economia.elpais.com/economia/2014/04/17/actualidad/1397736512 176300.html y archivo propio.

Morgan Stanley (USA) que, como se observa, está ligada al capital japonés, nos vincula igualmente a La Caixa/Caixabank (España) y La Caixa es accionista de Prisa y Telefónica, en España. Prisa mantiene estrechas relaciones con el mundo inversor de Estados Unidos así como presencia mediática (Reig, 2010a). Por ejemplo:

- A mediados de 2008, Unión Radio (la división de radio de Prisa, en alianza con el Grupo Godó, de Cataluña) controlaba más de 1.200 emisoras de radio en: España, EEUU, México, Colombia, Costa Rica, Panamá, Argentina y Chile, y anunció su expansión por Perú, Venezuela y los propios EEUU.

- En verano de 2009 forma la empresa PRISA IBN International, con IBN (USA), para promoción de productos audiovisuales en España, Portugal, América Latina y EEUU. Talos Partners, el brazo financiero de IBN, compró además una participación inicial del $4,5 \%$ del capital de PRISA.

- A principios del otoño de 2009 anuncia la venta del 25\% de Santillana a DLJ South American Partners, un fondo de capital privado que invierte en empresas privadas de Latinoamérica, con especial foco en Brasil, Chile y Argentina.

- En el último trimestre de 2010 se hace efectiva la entrada en el accionariado de Prisa del fondo de inversiones Liberty Acquisitions Holding.

Por su parte, la proyección internacional de Telefónica es evidente y llega también a Estados Unidos:

- En 2009, poseía las filiales hispanoamericanas de BellSouth (USA). 
- A finales de 2011-inicios de 2012 se une a Microsoft para promocionar Imagenio (una de sus plataformas de TV) en Internet.

- En mayo de 2014 vio cómo la compra de Direct TV por parte de AT\&T podría frustrar alguno de sus planes con América Latina: "El mercado de las telecomunicaciones se mueve a gran velocidad, sobre todo en Estados Unidos. Si en febrero fue Comcast la que anunció la compra de Time Warner Cable por $\mathbf{4 5 . 0 0 0}$ millones de dólares, ahora es el turno de AT\&T, que ultima la compra de la mayor plataforma de televisión por satélite, Direct TV. La operación podría superar los $\mathbf{3 6 . 0 0 0}$ millones de euros. Lo cierto es que con este movimiento, AT\&T se adelanta a Telefónica que, en su día, negoció con Direct TV, no para comprarla -la española no puede embarcarse en una operación de este calibre- sino para llegar a acuerdos comerciales que le permitieran ofrecer servicios de TV a sus clientes y así completar el cuádruple play en Hispanoamérica." [30]

De todas formas, la aparente desviación que acabo de consumar desde Prisa y Telefónica hacia Estados Unidos no es más que una pequeña demostración de cómo el enfoque estructural nos introduce de pronto en un laberinto de nombres y articulaciones muy difícil de dominar. Tengo que recordar que, en mi metodología, el hilo conductor actual estaba siendo Morgan Stanley. En la ilustración anterior anoté también:

- Entre los accionistas de Morgan Stanley están Mitsubishi UFJ Financial Group, Inc., BlackRock Institutional Trust Company, N.A. y JP Morgan Chase \& Company [31].

- BlackRock posee alrededor del 10\% de Televisa.

Otro de los nombres que han aparecido en las trayectorias profesionales de los ejecutivos (he elegido sólo tres) vinculados a Thomson Reuters es General Motors. Al margen de la decadencia de esta firma, me interesa saber algunos datos que subyacen a la marca. $Y$ compruebo que entre los accionistas de General Motors se encuentran JP Morgan Chase \& Company y BlackRock Institutional Trust Company, N.A. [32]. De nuevo BlackRock, además de la banca, sector omnipresente cuando se trata de grandes inversionistas y no tan grandes. Lo anterior se puede representar así en una diapositiva:

\section{Articulaciones}

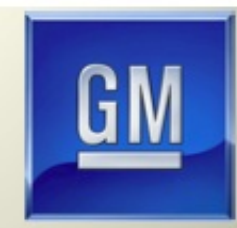

- Entre los accionistas de General Motors se encuentran JP Morgan Chase \& Company y BlackRock Institutional Trust Company, N.A.

- (https://es.finance.yahoo.com/q/mh?s=GM), consultado, 21/4/2014.

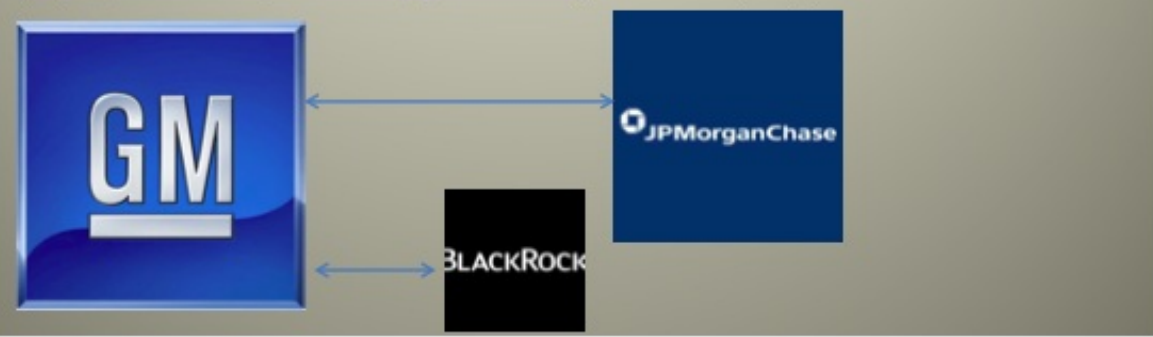

Nueva y lógica pregunta: ¿qué es BlackRock, que parece estar en todas partes? Blackrock es una entidad financiera estadounidense cuya sede central se encuentra en Nueva York. Está considerada como la mayor empresa de gestión de activos del mundo, se nos informa en la Red, a poco que se bucee en ella. Javier Checa indica al referirse a las relaciones de la corporación con la Bolsa española:

BlackRock, la mayor gestora de fondos del mundo, tiene a España muy presente en su particular foco inversor. 
En las últimas semanas, voces como las de César Alierta [máximo responsable de Telefónica] o Emilio Botín [máximo responsable del Grupo Santander] avisaban de que el dinero extranjero está entrando de forma sustancial en España. Para la firma estadounidense nuestro país no es territorio nuevo. Presente en todos los valores del lbex $\mathbf{3 5}$, el valor de sus inversiones alcanza los 9.000 millones de euros, posicionándole como uno de los jugadores más activos, con operaciones significativas prácticamente a diario en sus compañías en cartera. [33]

Ya sabemos algo, muy poco, de BlackRock en comparación con su auténtico poder. Aportaré y recordaré algo más. Para hacerlo, repito, aunque sea de forma mínima, me serviré de otra ilustración:

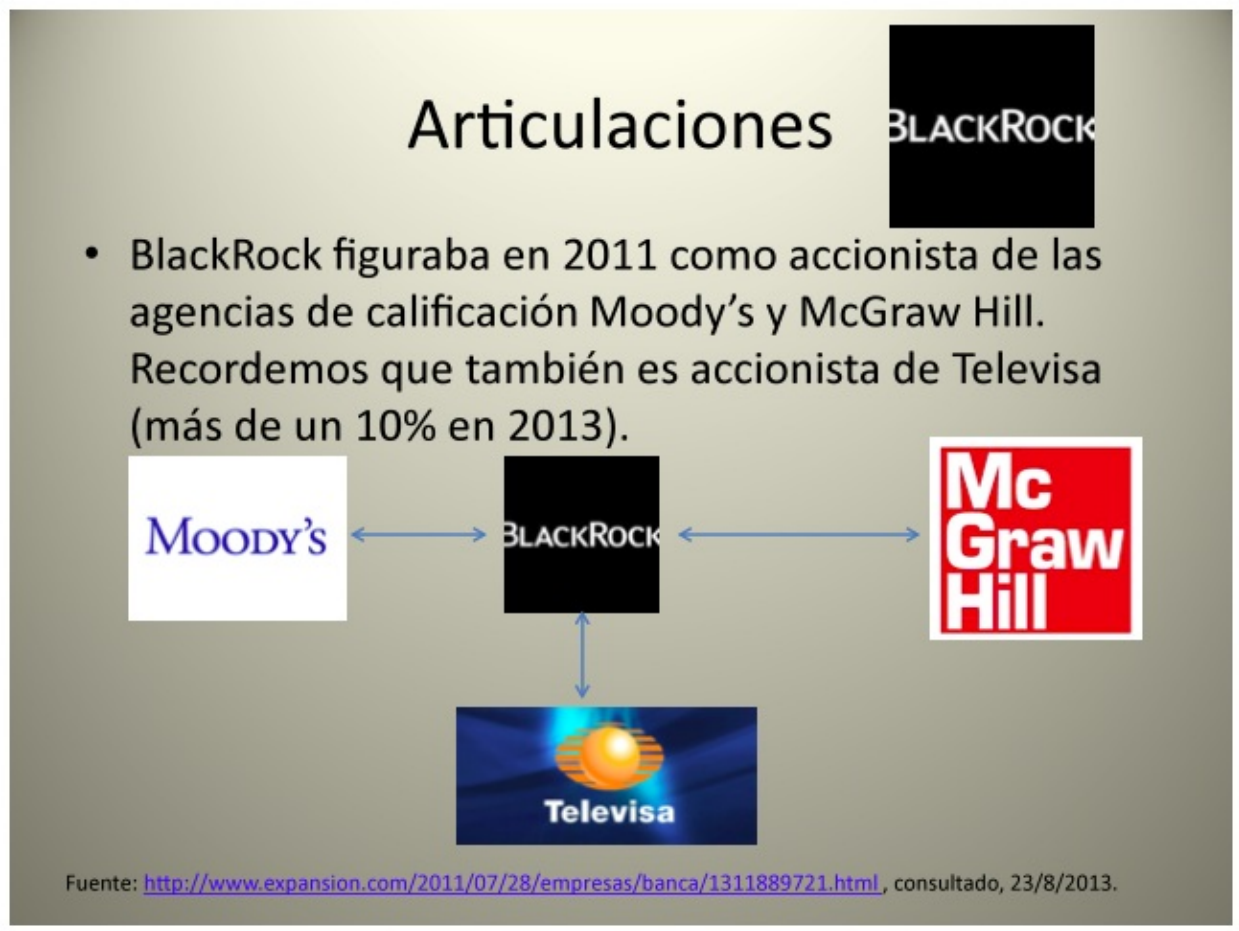

¿Y JP Morgan Chase que también respaldaba a General Motors? Dedicarse a esta potencia bancaria sería un trabajo aparte, al menos, pero en su día, estando en Miami, indagué sobre la propiedad del rotativo The Miami Herald. La resumí así:

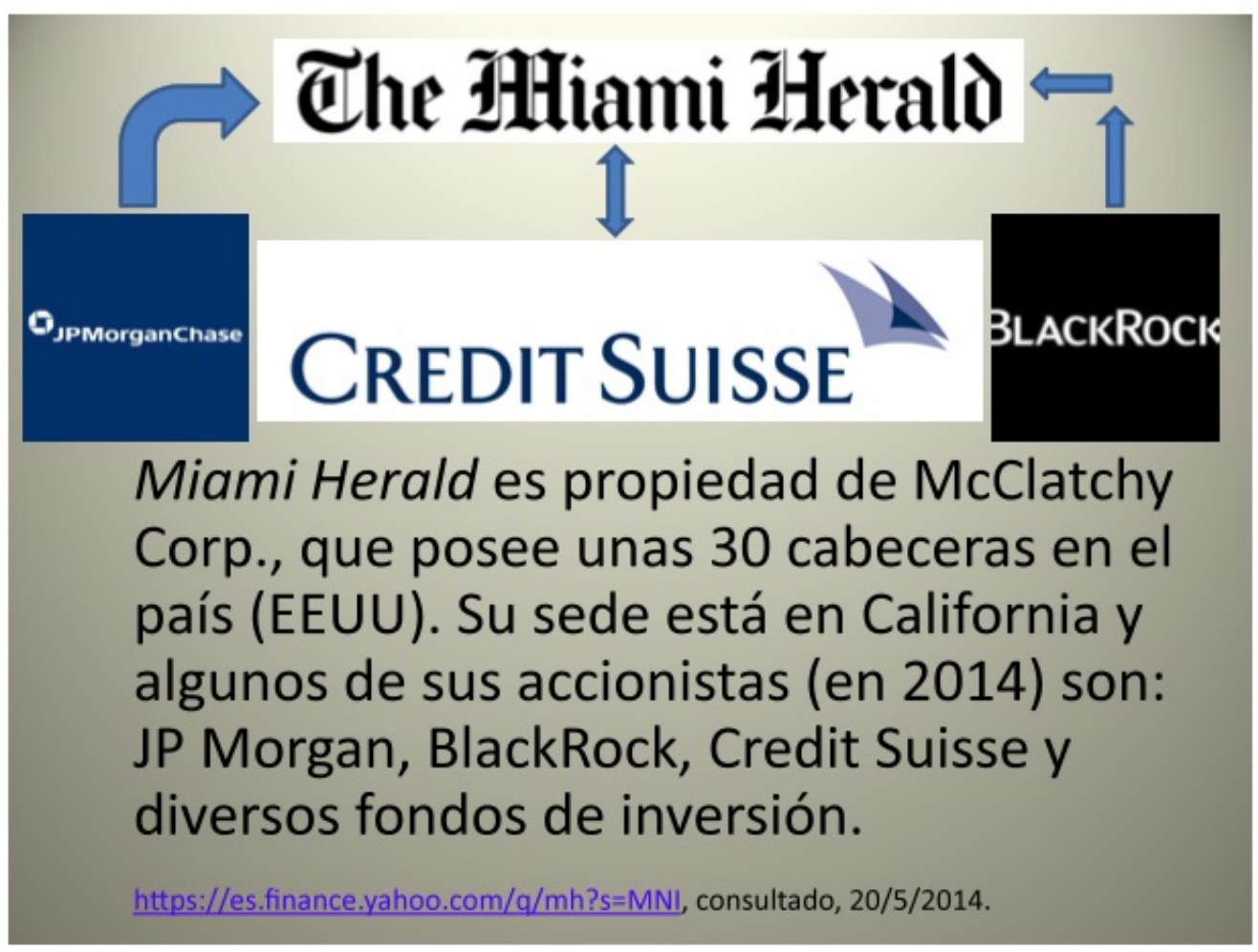


aceptó sin protestar- una multa del gobierno de los Estados Unidos de 1.800 millones de dólares por asesorar a ciudadanos estadounidenses para que evadieran impuestos al fisco de su país. "Se trata de una presentación de cargos poco frecuente por parte del Departamento de Justicia que no acostumbra a inculpar a firmas financieras, especialmente si son compañías globales que podrían llegar a desestabilizarse tras una acusación como esta. Esta es la primera vez en casi dos décadas que un banco admite su culpabilidad en un caso penal en Estados Unidos" [34]. Por supuesto, The Miami Herald se supone que no tiene culpa de nada pero sólo pretendo reflejar los compañeros de viaje que posee el mundo mediático y que, sin duda, influyen o pueden influir sobre las líneas editoriales [35].

Thomson Reuters -empresa matriz de JCR- nos está llevando ya demasiado lejos a pesar de que este texto son sólo simples esbozos de un poder muy complejo. Pero hay más, mucho más. Seleccionaré algunos otros datos que he descubierto.

Si BlackRock estaba presente en GM entonces debemos volver a GM y sus relaciones con el poder mediático así como con otras cuestiones relevantes. Podemos hacerlo de nuevo por medio de una ilustración:

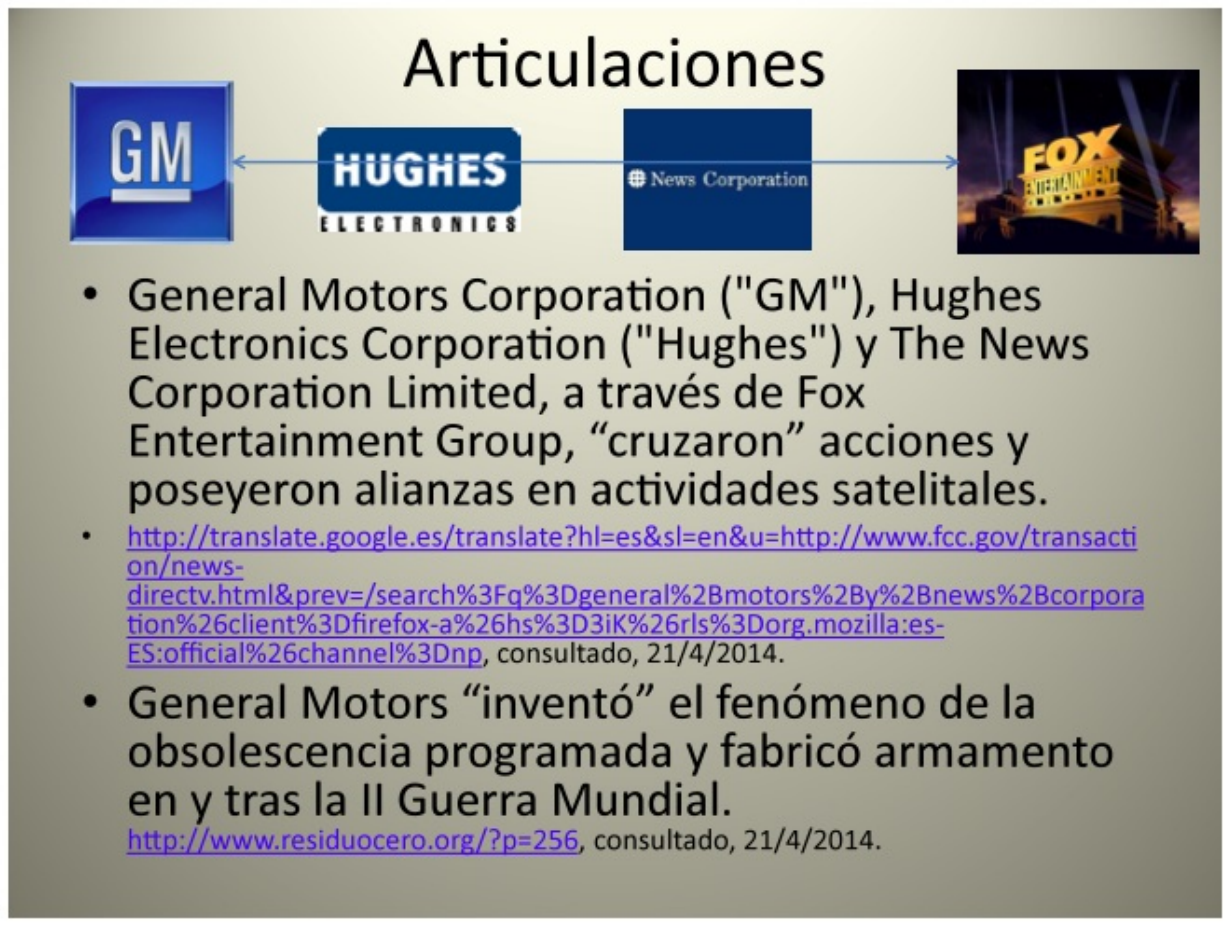

Como puede verse, una flecha atraviesa y enlaza a distintas corporaciones. Esas operaciones -menos la fabricación de armamento- sucedieron entre finales del siglo XX y el año 2006, aproximadamente. Y a ello sumamos el fenómeno de la obsolescencia programada, un buen invento para mantenernos "esclavos" del consumo innecesario, derivado de la producción en serie iniciada en el siglo XIX. Desde entonces, el mercado deberá "perseguir" y determinar la libertad del sujeto, tratando de llevarlo a su campo, algo para lo que será imprescindible otro elemento que añadir a las triquiñuelas tecnológicas: la publicidad elevada a ciencia para presentar lo anterior como una muestra de progreso.

Completaré lo que acabo de constatar con algunos datos adicionales que tienen en cuenta una pequeña perspectiva histórica:

- En mayo de 2014, Direct TV fue comprada casi en su totalidad por AT\&T [36].

- Ya en 2006, Direct TV había sido comprada casi toda a News Corp. (Murdoch) por parte de Liberty Media Group (John Malone).

- News Corp. compró Direct TV hacia 2003, en concreto se hizo con un 35\% de las acciones de Hughes Electronics, propietaria de Direct TV y, a su vez, poco antes, vinculada a General Motors.

Dije más arriba: nuestros ejecutivos de Thomson Reuters -"madre" de JCR- muestran en sus trayectorias vitales 
a empresas como:

- Morgan Stanley.

- General Motors.

- BlackRock.

- Hill and Knowlton

He tratado sobre algunas articulaciones de tres de ellas. ¿Por qué, además, he seleccionado, a Hill and Knowlton? Sencillamente por esta razón:

\section{Articulaciones HILL+KNOWLTON}

- Hill and Knowlton, inventó una historia falsa para convencer a los estadounidenses de la necesidad de expulsar a Sadam Hussein de Kuwait en 1991, algo que fue demostrado en el reportaje Vender la guerra. Ver: http://www.youtube.com/watch?v=Mr6h9zq03jo.

Las manipulaciones mediáticas suponen tratar a los ciudadanos de nuestras democracias como a niños. Puede que estemos ante niños adultizados o ante adultos aniñados -sobre todo si pensamos en Estados Unidos- pero aunque el fin justifique los medios, el aserto maquiavélico no debería aplicarse en una democracia a menos que nuestras democracias se asienten tan sólo en una palabra que es más deseo que realidad: democracia.

¿Cómo explicarles a los estadounidenses en 1991 que era necesario expulsar de Kuwait a Sadam Hussein si, en un alto porcentaje, no sabían ni qué era Kuwait ni quién era Sadam Hussein? No era efectivo emplear la razón y explicar didácticamente el problema, era más efectivo acudir a las emociones. ¿Qué es lo más enternecedor para nuestros sentimientos? Un niño. Y, ¿más que un niño? Un bebé. Y, ¿más que un bebé? Un bebé prematuro en una incubadora. Pues ya está, Hill and Knowlton inventó una historia y el tema lo destapó el reportaje-documental Vender la guerra [37]: los soldados de un ser malvado llamado Sadam habían entrado en los hospitales de un lugar llamado Kuwait, habían sacado a los bebés prematuros de sus incubadoras y, con sus bayonetas, los habían asesinado. Por tanto, había que eliminar de la faz de la tierra al malvado. Y los estadounidenses -perdonen la generalización, es una forma de hablar, como cuando The New York Times o Daily Telegraph acusan a los españoles de tener costumbres anacrónicas- [38] exclamaron: ¡Oh, que bombardeen y maten al maligno! Y así se hizo aunque como sabemos la eliminación física de Sadam y la exposición de su cadáver ante la plaza mediática para escarmiento de todos, llegó ya a comienzos del siglo XXI. En 1991 fue cuando un piloto estadounidense de un bombardero afirmó mientras arrojaba bombas contra Bagdad, por la noche, que desde el cielo aquellas bombas explotando parecían luces de Navidad. Y la prensa estadounidense se hizo eco de esta idea[39].

Si tiramos otra vez de la empresa Morgan Stanley llegaremos a BlackRock y ésta, entre otros nombres, nos 
conducirá hasta General Motors. Pero no olvidemos que Morgan Stanley también nos lleva a La Caixa (España) y que La Caixa nos lleva a Prisa (España). Sin embargo, Prisa posee más accionistas, además de Liberty o La Caixa. Un pequeño accionista de Prisa (con el 3\% de las acciones aproximadamente, en 2014) es el magnate mexicano Carlos Slim, a quien en los últimos años la revista Forbes sitúa entre los tres hombres más ricos del planeta. Slim, a través de su firma Carso, está presente también en The New York Times, como socio minoritario pero con un paquete accionarial en torno al 8\% en 2013.

El 18/11/2011, el buque insignia de Prisa, El País, afirmaba: "Slim adquiere un 3,2\% del capital del Grupo Prisa. El empresario mexicano, presente en el capital The New York Times, ha realizado la operación a través de Inmobiliaria Carso. (...).Además de PRISA, en España Slim controla el 0,202\% del capital de CaixaBank (antigua Criteria), de la que era consejero hasta que a principios de noviembre dejó su puesto para incorporarse al consejo de Criteria CaixaHolding, el holding de participaciones industriales de La Caixa." [40]. La llegada de Slim al Grupo Prisa, según la misma información, se produjo por acuerdo de los principales accionistas:

El grupo Timón, controlado por la familia Polanco, acordó con los accionistas significativos y consejeros, Nicolas Berggruen y Martin Franklin, presidente y cofundador respectivamente de Liberty Acquisition Holdings, la creación de una sociedad (special purpose vehicle) participada al $50 \%$ por ambas partes y controlada por Timón destinada a convertir 75 millones de warrants [41] en acciones por un importe de 150 millones de euros.

Sin embargo, una información posterior -de la Agencia EFE- iba aún más lejos. Es del 21 de febrero de 2014:

CIUDAD DE MÉXICO (EFE) - El empresario mexicano Carlos Slim y el grupo italiano Proto se convertirán en los principales accionistas del diario estadounidense New York Times (NYT), informaron este viernes fuentes de Proto Organization.

"Este acuerdo de participación conjunta por el 19\% del capital del NYT lo tomaron ayer en Nueva York directamente Carlos Slim y Alejandro Proto (presidente del grupo), y la operación se concretará la próxima semana", explicaron fuentes a la agencia EFE.

Los informantes declinaron mencionar el monto de esta operación, pero señalaron que ambos poseerán el 19\% del capital, de ellos Slim tendrá el $17 \%$ y Proto un $2 \%$.

Señalaron que con esta operación se convierten en los principales accionistas de la empresa, aunque aclararon que la línea editorial permanecerá en manos de los accionistas originales, la familia Ochs-Sulzberger.

$(\ldots)$

En un comunicado, Proto señaló que la venta del Washington Post al fundador de Amazon, Jeff Bezos, confirma la tendencia de que los grupos tradicionales por sí solos no pueden continuar en la operación de los grandes medios, sino que "necesitan un soporte sólido para superar la transición".

"Por esta razón, Proto Organization y su presidente Alessandro Proto, amigo de Carlos Slim, decidieron apoyar la compra de la mayoría accionaria de New York Times".

Proto es accionista de Prisa en España, del British Sky Broadcasting Group (BSkyB) en el Reino Unido y del grupo Rizzoli-Corriere della Sera en Italia.

$(\ldots)$

Slim le prestó al NYT 250 millones de dólares durante la crisis económica en 2009, después de las dificultades financieras por la caída en sus ingresos de publicidad. [42]

El Grupo Carso desmintió después la anterior información mientras que Proto insistió en que seguiría adelante solo para penetrar en The New York Times [43]. Estos dimes y diretes son frecuentes en el mundo coyuntural de los negocios. Aceptaré, por tanto, que el señor Slim solamente posee alrededor del $8 \%$ de las acciones de The New York Times: 


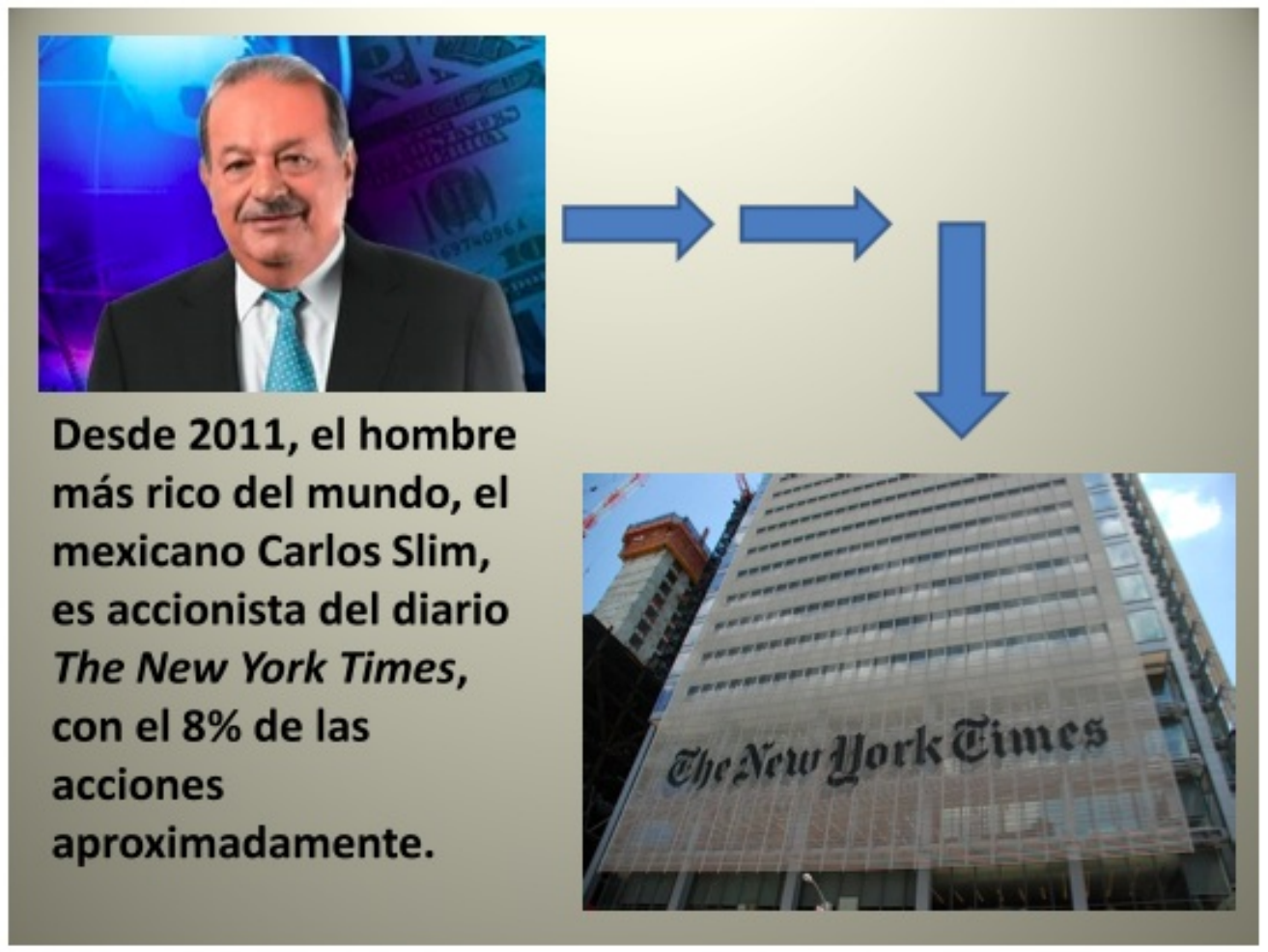

Demostrada la conexión de Carlos Slim no sólo con El País sino con The New York Times a través de la empresa Carso, la siguiente pregunta es igualmente obvia, eso al margen de hacer constar mi preocupación ante las palabras de Proto -nada nuevo pero no por ello menos alarmante- de que los medios necesitan apoyos extra-mediáticos. La pregunta es: ¿qué hay detrás de Carso? No tenemos más que mostrar una nueva ilustración para darnos cuenta del entramado de empresas que se esconde detrás de dicha palabra:

\section{El Grupo Carso: algunas empresas de Carlos Slim}

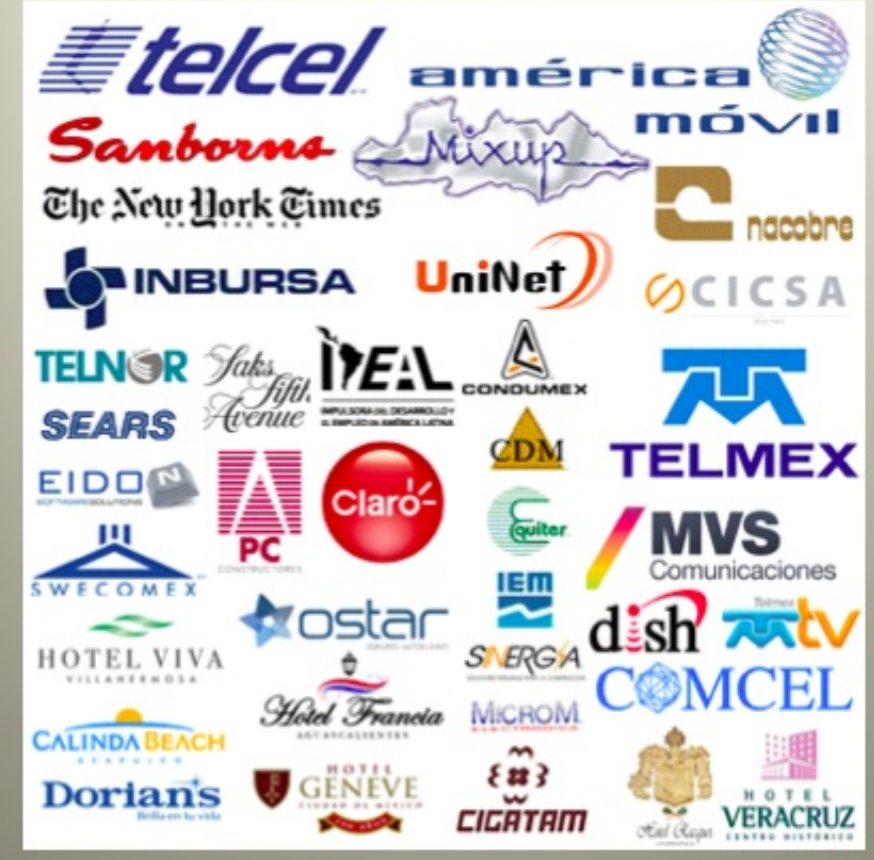

Una de ellas, como puede verse es The New York Times. Pero las hay de diversos sectores de la producción y para casi todos los gustos. Entonces me surge otra pregunta: ¿son realmente tan libres los periodistas de uno y otro medio para investigar cualquier tema que afecte a miles o millones de ciudadanos? ¿De verdad nos podemos creer que Carso va a respetar la independencia de sus medios participados? Y eso por no plantear otro enigma: ¿Qué porcentaje -directo e indirecto- posee realmente el señor Slim de una y otra cabecera?

Por otra parte, no voy a abordar aquí al Grupo Proto, impulsado por un personaje peculiar: Alessandro Proto 
sobre el que no he investigado apenas. Da la impresión de que es el típico inversor que se mete donde puede, desde las urbanizaciones de lujo y la construcción (en Argentina, por ejemplo) hasta los medios de comunicación [44]. Es curioso, también sostiene que sólo le interesa la inversión, o sea, la cuenta de resultados, no influir en las líneas editoriales de los medios. Entonces, ¿nadie influye en el mensaje mediático? A estas alturas es imposible sostener eso, está de sobra demostrado lo contrario (Chomsky y Herman, 1990, Serrano, 2009, Reig, 2010b y 2013) y aquí en este trabajo se han citado ejemplos.

Nuestro ejercicio estructural en torno a JCR nos ha llevado bastante lejos aunque, como se deducirá, el tema encierra varias investigaciones que nos conducirían a lugares aún más lejanos. La presencia de Thomson Reuters en la recámara de JCR permite indagar en no pocos entresijos. Al final, se desemboca en una maraña donde caben empresas y actividades muy diversas, casi ninguna relacionada con la comunicación, el periodismo y la investigación académica. Pero, eso sí, se supone que debemos creer en la transparencia y honestidad del sistema JCR y que no van a existir conflictos de intereses.

Me queda, para ir terminando, llevar a cabo una pequeña incursión en las editoriales que nos recomiendan a los investigadores como puntas de lanza para medir la calidad de nuestro trabajo. En España (Universidad de Sevilla) se nos aconsejan las siguientes marcas (en 2014):

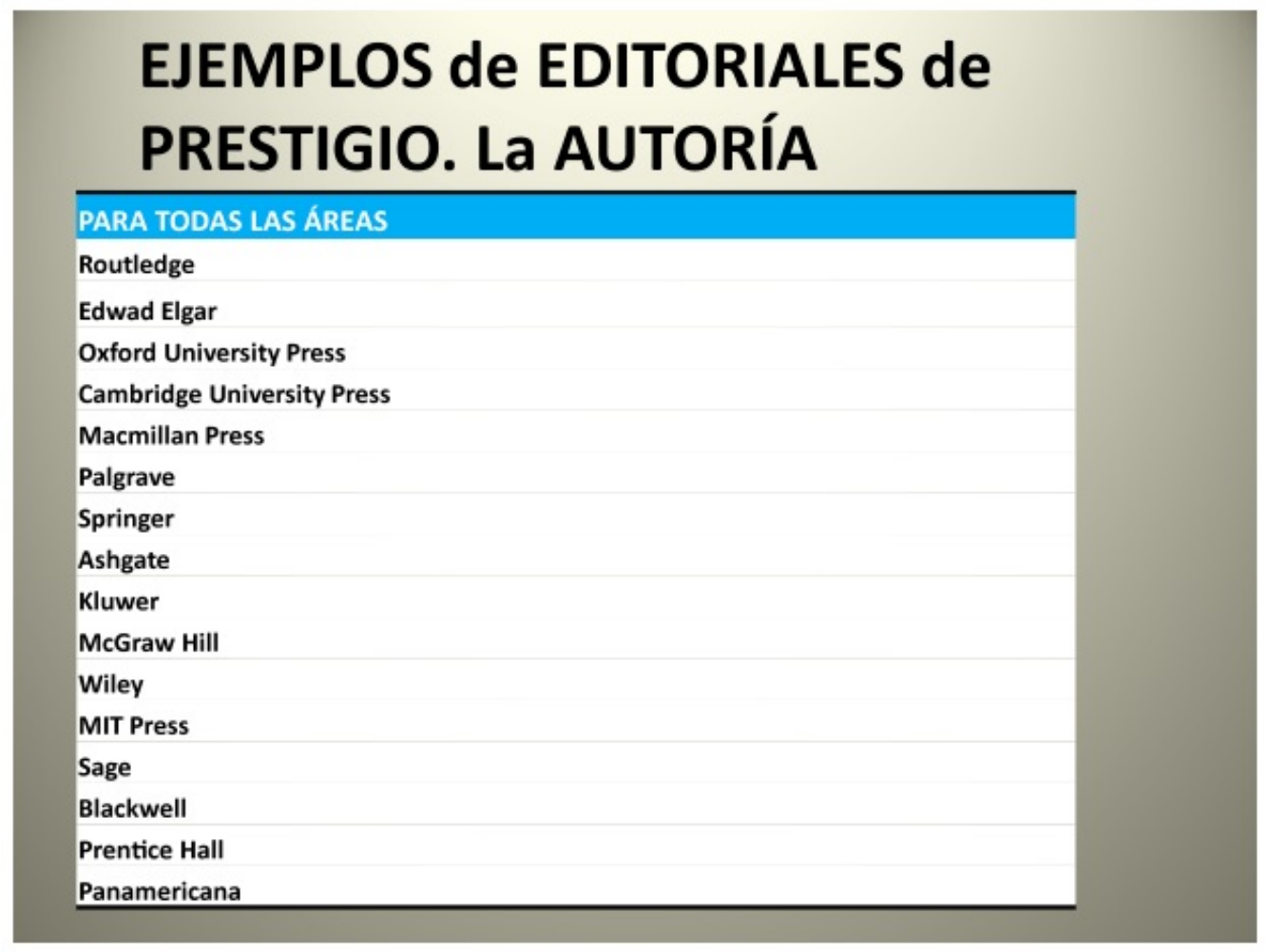

Como se observa, la investigación dependiente nos lleva, de nuevo, al mundo angloparlante. Sin negar su valor indudable a esta cultura y a sus excelentes aportaciones en ciencia, siendo fiel a mi metodología, es mi obligación preguntarme de nuevo a quién me aconsejan que dirija mi trabajo. Entonces encuentro algo que me permite aportar unas

\section{Mínimas articulaciones editoriales}

- McGraw Hill es una editorial, sí, pero también una agencia financiera de evaluación vinculada a BlackRock que es a su vez accionista de Morgan Stanley, vinculada a Thomson Reuters.

- Las editoriales Springer y Kluwer están vinculadas desde 2011 a Government of Singapore Investment Corporation, banco de inversiones de Singapur, después de pasar por diversas manos, entre ellas Axel Springer-Bertelsmann (D). Axel edita el diario Bild Zeitung (sensacionalista) y Bertelsmann, en unión con Pearson (RU) son dueños de la mayor editorial del mundo: Ramdon House.

- El Grupo Hearst Corporation (USA) posee el 40\% de la Agencia de Ráting Fitch Group (USA), en 2011. 
- En 2013, BlackRock Institutional Trust Co. poseía alrededor del 10\% de las acciones de Televisa (México) pero también en 2011 era accionista de Moody's (3,2\%) y McGraw Hill $(3,8 \%)$.

- «Moody's, Standard \& Poor's y Fitch levantan numerosas suspicacias en el Viejo Continente. José Manuel Durao Barroso les acusa de tener un sesgo antieuropeo, mientras que Herman Van Rompuy considera necesario romper su oligopolio y Angela Merkel reclama la creación de una agencia europea de calificación. Estas críticas sólo fueron contestadas por el principal accionista de Fitch, el francés Marc Ladreit de Lacharrière.» [45]

Es decir, los científicos sociales y de humanidades -que poseemos como una de nuestras obligaciones centrales cuestionarlo todo a fondo, o sea, ser realmente libres- nos vemos obligados a llevar a cabo un acto de fe en editoriales ligadas al mundo no editorial sino mercantil y además de esferas diversas de la producción. Por otra parte, ¿cómo se puede medir la calidad de las investigaciones sólo por publicar en editoriales concretas? Las editoriales llamadas "de prestigio" -como puede deducirse- suelen estar sumergidas en la dinámica negociadora. Conozco a colegas que se especializan en temas muy acotados. En mi campo, por ejemplo, en la comunicación y el periodismo centrados en el sur de España, ¿cómo y por qué exigir a estos investigadores que editen en firmas comerciales?

\section{CONCLUSIONES}

¿Es lo mismo conclusiones que propuestas? En esencia, sí. Por eso voy a terminar con conclusiones claras siendo consciente de que a lo largo de este trabajo he ido hilando algunas, motivo por el cual tal vez mis posibles evaluadores "ciegos" hubieran rechazado este artículo, entre otras razones como por ejemplo su redacción, como ya dije. Vayamos con esas conclusiones que son, a la vez, expresiones de descontento, inquietud y propuestas de mejora:

1. Ámbitos -y yo mismo- tendremos que adaptarnos a una realidad impuesta y/o aceptada "dócilmente". Dicha aceptación deberá ser revisada a fondo.

2. Eso no significa que no se ejerza una crítica implacable y tajante.

3. Es muy cuestionable que las investigaciones en Ciencias Sociales y, en concreto, en Comunicación y Periodismo, así como en Humanidades, de escuelas europeas y latinoamericanas, deban someterse a una situación como la que se acaba de describir, situación más cercana al mercado que a la ciencia. Más arriba lo he afirmado: las normas que el universitario español y latinoamericano ha elaborado no proceden exactamente de la tradición europea, española o latinoamericana, se supone que son necesarias y, como he sostenido una y otra vez, no pocos de mis colegas sénior las han aceptado, las promueven, las celebran y se han tornado en conversos, convencidos de que lo nuestro estaba corrupto de arriba abajo y, en lugar de arreglar el desaguisado sobre la base de nuestra Historia, se ha acudido a los principios de la cultura mercantil más hegemónica. El llamado pensamiento único no sólo se halla en la sociedad en general sino también en el mundo supuestamente científico.

4. Por tanto, en España y otros países se ha ido adoptando poco a poco un camino que tiene más que ver con la ideología implantada desde ciertos centros de poder mercantil que con los enfoques tradicionales españoles, europeos y latinoamericanos. El mundo latinoamericano y europeo deben ganar en dignidad investigadora, sin excluir a nada ni a nadie, es decir, sin la ortodoxia que se ha detectado en el mundo angloparlante. En este sentido, es intolerable que, por ejemplo, la Unión Europea (UE) haya negado su apoyo al portal europeo de Comunicación http://www.presseurop.eu/ que ha debido "congelar" su trabajo en diciembre de 2013 [46].

5. Por mucha "independencia" que posea JCR -división investigadora de Thomson Reuters- detrás de ella existe un entramado esencialmente mercantil y funcionalista que puede llevar al choque de intereses.

6. No se rechaza ni se niega la capacidad investigadora de Estados Unidos y menos sus indudables logros, lo que se reivindica aquí es un mayor protagonismo de la identidad europea en general y latina en particular. A un país se le puede admirar en algunos aspectos e imitar en lo que razonadamente sea necesario pero no mitificar y convertirse en su vasallo, colocando incluso en lugar secundario una cultura que ha costado milenios levantarla. 
7. Sin rechazar tampoco la indudable necesidad y utilidad del paper-sobre todo en determinados campos del saber- es preciso sostener que la sistematización del pensamiento y de la ciencia precisan del libro porque no podemos trasladar a la ciencia y al pensamiento el espíritu de "la sociedad de los 144 caracteres", puesta de moda por Twitter. Expresarse con rigor exige una superficie mayor y a veces mucho mayor y el problema no lo tiene quien utiliza esa superficie sino, en realidad, quienes la rechazan a causa de que obliga a llevar a término un sobreesfuerzo. Sin embargo, hay pocas cosas muy relevantes y relevantes en la vida que se hayan elaborado sin un gran esfuerzo donde, sí, debe tenderse a la economía de palabras pero no hasta llevarla a terrenos de puro acomodamiento y de pura mediocridad, relacionados con el deseo de intentar vivir en una eterna dinámica de la ley del mínimo esfuerzo.

8. La evaluación del trabajo de un investigador debe depender, sobre todo, del contenido de ese trabajo, quienes le evalúen deben acceder a la base primaria de referencia, no actuar únicamente a partir de otros factores como justificantes o lugares de publicación de supuesto prestigio. No se evalúa la ciencia y el quehacer cognitivo sólo con papeles sino con pruebas y conocimiento de causa.

9. El prestigio de bases de datos, revistas, editoriales, etc., no se otorga desde ningún lugar o institución monopólica o casi, sino, en todo caso, desde varios y numerosos lugares de distintas zonas del planeta, de distintas escuelas académicas, sin intromisión alguna de lo mercantil u otras estructuras o lobbies de poder.

10. Hay que tender hacia que los revisores o evaluadores de investigaciones sean explícitos y posean una trayectoria investigadora al menos igual o similar al autor evaluado y ser además de su campo específico de conocimiento.

\section{REFERENCIAS CITADAS}

\subsection{Principales}

Almiron, Nuria y Segovia, Ana I. (2008): Entrevista con Robert McChesney: "La lección de FreePress es una lección de política", en Revista de Economía Política de las Tecnologías de la Información y Comunicación , Eptic, Vol. X, núm. 1, enero/abril. Disponible en: http://issuu.com/eptic/docs/121028221818d04eaa1559404d34b1a3e3eba659a4e4\#embed

Argullol, Rafael (2014): "La cultura enclaustrada", en http://elpais.com/elpais/2014/03/25/opinion/1395742979_031566.html.

Boixadós, Ángel (2011): “¿Quiénes son los dueños de las agencias de ráting?” en: http://www.expansion.com/2011/07/28/empresas/banca/1311889721.html

Checa, Javier (2013): “Omnipresente BlackRock: la gestora tiene invertidos 9.000 millones en todo el Ibex", 4/11/2013, en: http://www.elconfidencial.com/mercados/fondos-de-inversion/2013-11-04/omnipresenteblackrock-la-gestora-tiene-invertidos-9-000-millones-en-todo-el-ibex_48379

Chomsky, Noam y Herman, Edward (1990): Los guardianes de la libertad. Propaganda, desinformación y consenso en los medios de comunicación de masas, Barcelona, Crítica.

Del Pino, Matilde (1999) (Traducción): Textos presocráticos, Barcelona, Edicomunicación.

Delgado-López-Cózar, Emilio and Ruiz-Pérez, Rafael and Jiménez-Contreras, E. (2006): La Edición de Revistas Científicas: Directrices, Criterios y Modelos de Evaluación, en:

http://www.fecyt.es/fecyt/docs/tmp/550433876.pdf.

Fernández-Armesto, Felipe (2014): "La ciencia y su lucha por la supervivencia”, en http://www.elmundo.es/opinion/2014/05/05/5367e595ca47417f398b457a.html.

Fernández Quijada, David (2008): "Revistas científicas e índices de impacto. A propósito de "Hacer saber", en Área Abierta № 20, Julio, 2008, Universitat Autònoma de Barcelona, en: 
http://eprints.rclis.org/15383/1/aa_20.pdf

Ferrer, Pablo (2014): “AT\&T se adelanta a Telefónica y ultima la compra de Direct TV”, 14/5/2014, en: http://www.hispanidad.com/Confidencial/att-se-adelanta-a-telefnica-y-ultima-la-compra-de-direct-tv-20140514162795.html.

Freud, Sigmund (2007): Psicología de las masas, Madrid, Alianza Editorial.

Giordano, Eduardo (sin año): "El control de las fuentes audiovisuales en la propaganda bélica”, en la revista Comunicación, de Venezuela: http://gumilla.org/biblioteca/bases/biblo/texto/COM199175_37-64.pdf.

Harris, Marvin (2000): Teorías sobre la cultura en la era posmoderna, Barcelona, Crítica.

Herman, Edward S. \& McChesney, Robert W. (1997): The Global Media: The New Missionaries of Corporate Capitalism, London and Washington, Cassell.

Herrán, A. de la y Villena, J.L. (2012). La 'cultura del impacto JCR': El caso del área de Didáctica y Organización Escolar. En A. de la Herrán y J. Paredes (Coords.), Promover el cambio pedagógico en la universidad. Madrid, Pirámide (Colección ‘Pedagogía y Didáctica').

León Duarte, Gustavo Adolfo (2007): Sobre la Institucionalización del Campo Académico de la Comunicación en América Latina. Una Aproximación a las Características Estructurales de la Investigación Latinoamericana en Comunicación, Tesis Doctoral, dirigida por el Dr. Miquel Rodrigo Alsina, Universidad Autónoma de Barcelona. Disponible en: http://www.tdx.cat/bitstream/handle/10803/4196/gald1de1.pdf?sequence=1.

Marques de Melo, José (2009): Pensamiento comunicacional latinoamericano. Entre el saber y el poder, Sevilla/Zamora, Comunicación Social Ediciones y Publicaciones.

Masip, Pere (2005): "European Research in Communication during the years 1994-2004: a Bibliometric Approach", comunicación presentada en First European Communication Conference, European Communication Research and Education Association, Amsterdam, 24 a 26 de noviembre. 2005.

Merrill, John, Lee, John y Friedlander, Edward Jay (1992): Medios de comunicación social. Teoría y práctica en Estados Unidos y en el mundo, Madrid, Fundación Germán Sánchez Ruipérez. Versión original: Modern Mass Media, Published by arrangement with HarperCollins Publishers Inc.

Moragas Spà, Miquel de (2011): Interpretar la comunicación. Estudios sobre medios en América y Europa . Barcelona, Gedisa.

Navarro, Viçent (2013): “Lo que la película 'Lincoln' no dice sobre Lincoln”, en Público.es, http://blogs.publico.es/dominiopublico/6405/lo-que-la-pelicula-lincoln-no-dice-sobre-lincoln/, 17/1/2013.

Neuman, W.L. (1994): Social Research Methods. Qualitative and Quantitative Approaches, Massachusetts, Needham Heights.

Nietzsche, Friedrich (1999): Así hablaba Zaratustra, Barcelona, Edicomunicación.

Reig, Ramón (2013): "La correlación estructura socio-económico-mediática y mensajes: aportaciones desde el análisis de la comunicación mercantil", Question. Revista Especializada en Periodismo y Comunicación, Universidad de La Plata, Argentina, Vol. 1, No 40 (octubre-diciembre 2013). Disponible en: http://perio.unlp.edu.ar/ojs/index.php/question/article/view/1981/1729.

Reig, Ramón (2011a): Los dueños del periodismo. Claves de la estructura mediática mundial y de España, Barcelona, Gedisa.

Reig, Ramón (2011b): Todo Mercado. Contra la simplicidad del pensamiento crítico, Barcelona, Anthropos.

Reig, Ramón (2010a): “Condicionantes estructurales del trabajo del periodista. Las causas de una sociedad 
desinformada", Global Media Journal México, Volumen 7, Número 14 Pp. 39-59. Disponible en: http://132.248.9.34/hevila/Globalmediajournalenespanol/2010/vol7/no14/3.pdf.

Reig, Ramón (2010b): La telaraña mediática. Cómo conocerla, cómo comprenderla, Sevilla/Zamora, Comunicación Social Ediciones y Publicaciones.

Schopenhauer, Arthur (2012): El arte de conocerse a sí mismo, Madrid, Alianza Editorial.

Serrano, Pascual (2009): Desinformación. Cómo los medios ocultan el mundo, Barcelona, Península.

Soriano, Jaume (2008): "El efecto ANECA", disponible en: http://www.ae-

ic.org/santiago2008/contents/pdf/comunicaciones/286.pdf.

\subsection{Otros enlaces a Internet (webs, hemerografía y videos)}

http://periodistica.es/

http://www.elconfidencial.com/comunicacion/2013/04/01/prisa-pone-el-pais-como-garantia-ante-los-bancospara-sobrevivir-117922/.

http://www.expansion.com/2012/03/09/empresas/energia/1331282897.html?

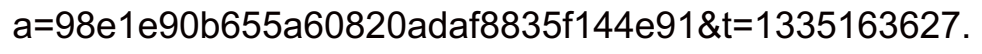

http://ruedadelafortuna.com.mx/tag/grupo-carso/.

http://correlavozcomitan.com.mx/la-riqueza-de-carlos-slim-helu-a-costa-de-los-mexicanos.

http://www.abcdesevilla.es/sociedad/20130810/abci-jeff-bezos-villafrechos-amazon-201308101127.html http://www.youtube.com/watch?v=FnD3-mkGAkA.

http://www.youtube.com/user/ShadowsofLibertyDoc

http://www.youtube.com/watch?v=eYSj0k2aY-s.

http://blogs.publico.es/dominiopublico/6405/lo-que-la-pelicula-lincoln-no-dice-sobre-lincoln/

http://www.elmundo.es/opinion/2014/05/05/5367e595ca47417f398b457a.html

http://elpais.com/elpais/2014/03/25/opinion/1395742979_031566.html

http://www.projectcensored.org

http://www.freepress.net/

http://hindexscholar.com/ciencias-sociales/comunicacion/periodismo/

http://thomsonreuters.com/journal-citation-reports/.

http://www.elmundo.es/elmundo/2008/03/27/comunicacion/1206607545.html.

http://economia.elpais.com/economia/2014/04/17/actualidad/1397736512_176300.html

https://es.finance.yahoo.com/q/mh?s=MS.

https://es.finance. $y a h o o . c o m / q / m h ? s=G M$.

https://es.finance.yahoo.com/q/mh?s=MNI 
http://www.rtve.es/noticias/20140520/credit-suisse-pagara-multa-1800-millones-euros-eeuu-fraudefiscal/940400.shtml

http://www.hispanidad.com/Confidencial/att-se-adelanta-a-telefnica-y-ultima-la-compra-de-direct-tv-20140514162795.html.

http://www.youtube.com/watch?v=Mr6h9zqO3j0.

http://www.nytimes.com/2014/02/18/world/europe/spain-land-of-10-pm-dinners-ponders-a-more-standardtime.html?hpw\&rref=world\&_r=1.

http://www.elconfidencial.com/espana/2014-02-18/las-costumbres-espanolas-en-the-new-york-times-siestas-ycenas-a-las-22-00_91101/

http://www.abc.es/sociedad/20140220/abci-desmontando-falsos-mitos-espanoles-201402191222.html http://www.antena3.com/noticias/economia/the-telegraph-insta-espana-abandonar-cultura-siesta-salircrisis_2013092400137.html.

http://economia.elpais.com/economia/2011/11/18/actualidad/1321605179_850215.html.

http://www.bolsamadrid.es/esp/Warrants/Warrants.aspx

http://www.cnnexpansion.com/negocios/2014/02/21/slim-accionista-mayoritario-en-nyt

http://www.elnortedecastilla.es/agencias/20140225/economia/proto-seguira-adelante-proyectoinversion_201402252127.html.

http://vozpopuli.com/economia-y-finanzas/17197-alessandro-proto-compra-un-1-75-de-prisa-y-negocia-hacersecon-el-15-de-el-pais,

http://noticias.lainformacion.com/economia-negocios-y-finanzas/construccion-e-inmobiliaria/grupo-italiano-protoplanea-invertir-100-millones-de-euros-en-argentina_TCZGP25f1yQVY4yAmfbix3/.

\subsection{Enlaces hacia editoriales españolas de prestigio que publican importantes investigaciones sobre Comunicación (teoría y práctica)}

http://www.comunicacionsocial.es/.

http://www.gedisa.com/articulos.aspx?modo=c\&fam=1023. http://www.gedisa.com/articulos.aspx?

modo $=c \&$ fam $=1022$.

http://www.fragua.es/.

http://ariel.claudator.com/coleccion/ariel-comunicacion.

http://www.sintesis.com/ciencias-de-la-informacion-7/.

http://www.rtve.es/instituto/publicaciones/.

http://www.revistalatinacs.org/067/cuadernos/artesanos.html.

http://www.grupocomunicar.com/index.php?contenido=publicaciones.

[1] Hay expertos que, cuando tratan sobre los "Criterios para la aceptación de manuscritos" en revistas 
científicas, constatan como uno de los aspectos positivos de la presentación de los mismos: "buena redacción (claridad, brevedad, precisión), buena organización (coherencia lógica) y buena presentación material". Los periodistas académicos puede que tengamos muchos defectos pero desde luego el estilo periodístico es el que mejor cumple con los requisitos anteriores. Véase: Delgado-López-Cózar, Emilio and Ruiz-Pérez, Rafael and Jiménez-Contreras, E. La Edición de Revistas Científicas: Directrices, Criterios y Modelos de Evaluación. , 2007, en: http://www.fecyt.es/fecyt/docs/tmp/550433876.pdf, p. 200, consultado, 8/5/2014. No es que sea un estilo exactamente igual que el que podemos aplicar en los medios pero sí huye de la exhibición rocambolesca de palabras pretendidamente científicas.

[2] Este paper no me va a servir de nada en mi país, España, para imprimirle más calidad a mi curriculum, al contrario, me puede perjudicar porque, ¿qué es eso de que alguien se atreva a editar sus reflexiones, análisis, estudios e investigaciones en la misma revista que dirige? Se supone que soy una especie de sujeto deshonesto, poseo la presunción de culpabilidad, no de inocencia, porque no he sido evaluado por pares o tríos "ciegos" o identificados ni esta revista es JCR, por ahora. Y, sin embargo, ¿no es lógico que un investigador o equipo de investigadores den a conocer sus trabajos en su revista? No, porque tienen la presunción de culpabilidad, son presuntamente culpables de corrupción académica, digámoslo así. Todo investigador que actúe de esta forma es sospechoso de tráfico de influencias.

[3] No revelaré mis fuentes de información para afirmar esto con el fin de no comprometerlas y porque no tengo sus permisos pero proceden tanto de España como de Estados Unidos.

[4] Delgado-López-Cózar, Emilio and Ruiz-Pérez, Rafael and Jiménez-Contreras, E. La Edición de Revistas Científicas: Directrices, Criterios y Modelos de Evaluación., 2007, en: http://eprints.rclis.org/13943/ y http://www.fecyt.es/fecyt/docs/tmp/550433876.pdf, pp. 187-188, consultado, 8/5/2014.

[5] El curriculum de McChesney es abrumador, con aproximadamente 200 páginas. Para quienes estudiamos las estructuras mediáticas nos ha sido de especial interés un texto ya clásico, escrito con Herman, que, en cierta manera, enlaza con Bagdikian y su célebre Media monopoly. Se trata de: Herman, Edward S. \& McChesney, Robert W. (1997): The Global Media: The New Missionaries of Corporate Capitalism, London and Washington, Cassell. Sus colaboraciones con Chomsky y Ralp Nader son también especialmente interesantes.

[6] Véase: http://www.elconfidencial.com/comunicacion/2013/04/01/prisa-pone-el-pais-como-garantia-ante-losbancos-para-sobrevivir-117922/.

[7] Ver: http://www.expansion.com/2012/03/09/empresas/energia/1331282897.html?

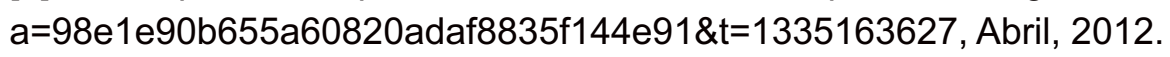

[8] Ver: http://ruedadelafortuna.com.mx/tag/grupo-carso/, 27/2/2014.

[9] Ver: http://correlavozcomitan.com.mx/la-riqueza-de-carlos-slim-helu-a-costa-de-los-mexicanos.

[10] Aquí me surge otro problema para que mi paper sea de calidad y referencia, digno de figurar en una revista indexada o bien JCR, el Olimpo de las revistas indexadas, la super-indexación. ¿Cuántas veces me puedo auto-citar? Es que si pasan no sé si de tres o cuatro veces ya pierde calidad mi artículo. No sólo me atrevo a editarlo en la revista que yo mismo dirijo sino que, además, ¡me autocito muchas veces! ¡Es el colmo de la falta de honradez y de la desvergüenza! ¡Y nadie me ha evaluado! ¡No he tenido revisores! ¡Me lo he guisado y me lo he comido yo solo! ¡Solo! No lo he elaborado en equipo, con lo que eso se valora en estos tiempos aunque Freud, por ejemplo, afirmara que las grandes obras se tejen en soledad (Freud, 2007). ¡Diablos! ¡He citado un libro en lugar de un paper! ¡Estoy perdido! Y, además, ¿qué forma de escribir es ésta?, ¿qué ciencia es ésta? No, es un ensayo o, mejor, un panfleto, un libelo. No tiene ni estilo periodístico, tiene estilo de taberna. ¿Cómo se atreve a presentar algo de esta forma un tipo tan importante como yo que tiene tres sexenios de investigación reconocidos y lleva casi veinticinco años en la universidad?

[11] Véase: Marina Pina / Villafrechós (Valladolid), 10/08/2013, en: http://www.abcdesevilla.es/sociedad/20130810/abci-jeff-bezos-villafrechos-amazon-201308101127.html y Diario www.publico.es, 6/8/2013. 
[12] Ver: Sombras de libertad, en Documentos TV (TVE2, junio 2013). Enlace: http://www.youtube.com/watch? $\mathrm{v}=$ FnD3-mkGAkA.

Versión en inglés: http://www.youtube.com/user/ShadowsofLibertyDoc. Para comprobar la influencia negativa en el trabajo del periodista, Reig, Ramón (2010a): "Condicionantes estructurales del trabajo del periodista. Las causas de una sociedad desinformada”, Global Media Journal México, Volumen 7, Número 14 Pp. 39-59. Disponible en: http://132.248.9.34/hevila/Globalmediajournalenespanol/2010/vol7/no14/3.pdf.

[13] La desconfianza hacia el periodismo se vio clara en Estados Unidos cuando en 2004 se dio a conocer el informe El estado de los medios de comunicación 2004, editado por The Project for Excellence in Journalism (PEJ). Para otras zonas, Japón, por ejemplo, léase: http://espanol.ipcdigital.com/2012/11/27/confianza-dejaponeses-en-medios-de-comunicacion-cae-a-minimo-historico

[14] Ver: http://www.youtube.com/watch?v=ylT3QuD5wdM y http://www.youtube.com/watch?v=Vfpw3mwjLLk, el segundo de los enlaces contiene una estúpida advertencia puritana por la que no se recomienda que vean el documental jóvenes menores de 15 años, con argumentos peregrinos tales como que el texto incluye violencia o lenguaje vulgar.

[15] Enlace en inglés con subtítulos en español: http://www.youtube.com/watch?v=eYSj0k2aY-s.

[16] Leer, Navarro, Viçent (2013): “Lo que la película 'Lincoln' no dice sobre Lincoln”, en Público.es, http://blogs.publico.es/dominiopublico/6405/lo-que-la-pelicula-lincoln-no-dice-sobre-lincoln/, 17/1/2013. El profesor Navarro es Catedrático de Ciencias Políticas y Políticas Públicas, Universidad Pompeu Fabra, y Profesor de Policy Studies and Public Policy, The Johns Hopkins University.

[17] Mis teóricos evaluadores "ciegos" (demasiado ciegos, tal vez, y sordos) me hubieran objetado que lanzo opiniones y juicios de valor en mi artículo. Por tanto, no es válido para ser publicado, según tal ortodoxia académica, que nos condena a los investigadores ya veteranos en ciencias sociales y en comunicación y periodismo a no poder exponer creando, interpretando, como si estuviéramos en otros campos del saber. Por tanto, buena parte de la ciencia paleontológica, pongamos por caso, es, en cierta medida, no ciencia, porque se dedica a interpretar y a especular a partir de un trozo de mandíbula o de cualquier otro resto homínido o humano. Por mucho que "hable" ese trozo de hueso, en cierta medida o en gran medida, lo que hacía cuando estaba vivo no deja de ser especulativo.

[18] http://www.elmundo.es/opinion/2014/05/05/5367e595ca47417f398b457a.html

[19] http://elpais.com/elpais/2014/03/25/opinion/1395742979_031566.html

[20] No es el momento de detenerse en este tema pero queda abierto para otro trabajo posterior que no necesariamente debe ser escrito por mí. Pero vaya por delante que los mayores "enemigos" de la UE, en Europa, al menos, hablan en ingles.

[21] He seguido el tema desde finales del siglo XX hasta mediados de la primera mitad del XXI y puedo aportar pruebas del hecho que ahora no vienen al caso para no extender más este trabajo. Además el asunto es de sobra conocido en la comunidad científica.

[22] H Index Scholar (http://hindexscholar.com/ciencias-sociales/comunicacion/periodismo/) es un índice bibliométrico que pretende medir el rendimiento de la producción académica de los profesores e investigadores de universidades públicas españolas de Humanidades y Ciencias Sociales a partir del recuento de sus publicaciones y de las citas bibliográficas que estas han recibido a través de Google Scholar. La medición de la producción y el impacto de las publicaciones científicas, que son el principal medio empleado por los científicos para dar a conocer los resultados de sus creaciones, se ha convertido en el instrumento por excelencia para determinar la relevancia e importancia y, subsidiariamente, la calidad de la actividad científica.

[23] Delgado-López-Cózar, Emilio and Ruiz-Pérez, Rafael and Jiménez-Contreras, E. (2006): La Edición de Revistas Científicas: Directrices, Criterios y Modelos de Evaluación, en:

http://www.fecyt.es/fecyt/docs/tmp/550433876.pdf. 
[24] Analizar los entes de los que emanan los mensajes o los modelos a seguir, los arquetipos, sean del tipo que sean, es una de las personalidades y señas de identidad de la materia universitaria Estructura de la Información desde que se creara en España a principios de los años 70 del siglo XX (Reig, 2010b). La tarea es importante porque hay que saber en manos de quiénes estamos.

[25] Daniel Torres-Salinas y Emilio Delgado López-Cózar en power point facilitadio por la Universidad de Sevilla, 2013.

[26] Moragas estudia las corrientes investigadoras no sólo de España y América Latina sino de Estados Unidos y otros países. Marques de Melo y León Duarte -éste último dirigido por Miquel Rodrigo Alsina, otro estudioso del tema- se centran en América Latina. Se trata de una constante en el mundo bibliográfico español: la constatación de la actividad investigadora en Comunicación y Periodismo. Por otra parte, si el lector desea comprobar la relevancia que editoriales españolas notorias le otorgan a la investigación en Comunicación y Periodismo así como la riqueza temática de dicha investigación en el ámbito de habla hispana -sobre todo- no tiene más que conectar con estas webs, entre otras: http://www.comunicacionsocial.es/, http://www.gedisa.com/articulos.aspx?modo=c\&fam=1023, http://www.gedisa.com/articulos.aspx? modo=c\&fam=1022, http://www.fragua.es/, http://ariel.claudator.com/coleccion/ariel-comunicacion, http://www.sintesis.com/ciencias-de-la-informacion-7/. Para un enlace que haga hincapié sobre todo en la práctica de la Comunicación: http://www.rtve.es/instituto/publicaciones/.

[27] Soriano, Jaume (2008): "El efecto ANECA", disponible en: http://www.aeic.org/santiago2008/contents/pdf/comunicaciones/286.pdf

[28] http://thomsonreuters.com/journal-citation-reports/, web oficial de Thomson Reuters, consultada, 25/4/2014.

[29] http://www.elmundo.es/elmundo/2008/03/27/comunicacion/1206607545.html, consultado, 20/4/2014.

[30] Pablo Ferrer: "AT\&T se adelanta a Telefónica y ultima la compra de Direct TV", 14/5/2014, en: http://www.hispanidad.com/Confidencial/att-se-adelanta-a-telefnica-y-ultima-la-compra-de-direct-tv-20140514162795.html.

[31] https://es.finance.yahoo.com/q/mh?s=MS, consultado, 21/4/2014.

[32] https://es.finance.yahoo.com/q/mh?s=GM, consultado, 21/4/2014.

[33] Javier Checa: "Omnipresente BlackRock: la gestora tiene invertidos 9.000 millones en todo el Ibex", 4/11/2013, en: http://www.elconfidencial.com/mercados/fondos-de-inversion/2013-11-04/omnipresenteblackrock-la-gestora-tiene-invertidos-9-000-millones-en-todo-el-ibex_48379/, consultado, 16/5/2014.

[34] http://www.rtve.es/noticias/20140520/credit-suisse-pagara-multa-1800-millones-euros-eeuu-fraudefiscal/940400.shtml, consultado, 20/5/2014.

[35] Reig, Ramón (2013): "La correlación estructura socio-económico-mediática y mensajes: aportaciones desde el análisis de la comunicación mercantil”, Question. Revista Especializada en Periodismo y Comunicación, Universidad de La Plata, Argentina, Vol. 1, No 40 (octubre-diciembre 2013). Disponible en: http://perio.unlp.edu.ar/ojs/index.php/question/article/view/1981/1729. Espero que al Dr. Eugene Garfield y "herederos" esta revista académica les parezca digna de ser considerada ahora o en el futuro como digna de ser una de las elegidas para la gloria científica.

[36] Ver: http://www.hispanidad.com/Confidencial/att-se-adelanta-a-telefnica-y-ultima-la-compra-de-direct-tv20140514-162795.html.

[37] http://www.youtube.com/watch?v=Mr6h9zqO3j0.

[38] Ver artículo original: http://www.nytimes.com/2014/02/18/world/europe/spain-land-of-10-pm-dinnersponders-a-more-standard-time.html?hpw\&rref=world\&_r=1. Repercusiones en España en:

http://www.elconfidencial.com/espana/2014-02-18/las-costumbres-espanolas-en-the-new-york-times-siestas-y- 
cenas-a-las-22-00_91101/, http://www.abc.es/sociedad/20140220/abci-desmontando-falsos-mitos-espanoles201402191222.html y http://www.antena3.com/noticias/economia/the-telegraph-insta-espana-abandonarcultura-siesta-salir-crisis_2013092400137.html.

[39] Véase Giordano, Eduardo: "El control de las fuentes audiovisuales en la propaganda bélica”, en la revista Comunicación, de Venezuela: http://gumilla.org/biblioteca/bases/biblo/texto/COM199175_37-64.pdf, p. 17. Para los "ortodoxos" del mercado, no hace falta que la consulten, como procede de Venezuela, seguro que miente. Pero, lamentablemente, no es así, yo estaba frente al televisor escuchando y contemplando la "guerra televisada". ¿También miento?

[40] http://economia.elpais.com/economia/2011/11/18/actualidad/1321605179_850215.html.

[41] Un warrant es un valor negociable emitido por una entidad a un plazo determinado que otorga el derecho (y no la obligación) mediante el pago de un precio a comprar (warrant tipo call) o vender (warrant tipo put) una cantidad específica de un activo (activo subyacente) a un precio prefijado a lo largo de toda la vida del mismo o en su vencimiento según su estilo. Ver: http://www.bolsamadrid.es/esp/Warrants/Warrants.aspx. Nota aclaratoria mía, no de la información de EFE. .

[42] http://www.cnnexpansion.com/negocios/2014/02/21/slim-accionista-mayoritario-en-nyt. Consultado, 16/5/2014. BSkyB ha estado controlada por News Corp., de Murdoch, y Rizzolli Corriere della Sera por Fiat, de la familia Agnelli, presente además en la industria de armamento.

[43] http://www.elnortedecastilla.es/agencias/20140225/economia/proto-seguira-adelante-proyectoinversion_201402252127.html.

[44] http://vozpopuli.com/economia-y-finanzas/17197-alessandro-proto-compra-un-1-75-de-prisa-y-negociahacerse-con-el-15-de-el-pais, 15/11/2012, http://noticias.lainformacion.com/economia-negocios-yfinanzas/construccion-e-inmobiliaria/grupo-italiano-proto-planea-invertir-100-millones-de-euros-enargentina_TCZGP25f1yQVY4yAmfbix3/, 17/2/2014, consultado, 15/5/2014.

[45] Ángel Boixadós: “¿Quiénes son los dueños de las agencias de ráting?”, 29/7/2011, en: http://www.expansion.com/2011/07/28/empresas/banca/1311889721.html.

[46] http://www.presseurop.eu/es/content/press-review/4419221-se-cierra-una-ventana-la-vida-de-los-europeos.

Breve semblanza del autor: Ramón Reig es Catedrático de Estructura de la Información y Director de Ámbitos. Revista Internacional de Comunicación.

Ámbitos. Revista Internacional de Comunicación, n.27, año 2014, cuarto trimestre (invierno). 